2017-06

The challenges and opportunities of addressing particle size effects in sediment source fingerprinting: A review

\author{
Laceby, JP
}

http://hdl.handle.net/10026.1/9622

10.1016/j.earscirev.2017.04.009

Earth-Science Reviews

Elsevier BV

All content in PEARL is protected by copyright law. Author manuscripts are made available in accordance with publisher policies. Please cite only the published version using the details provided on the item record or document. In the absence of an open licence (e.g. Creative Commons), permissions for further reuse of content should be sought from the publisher or author. 


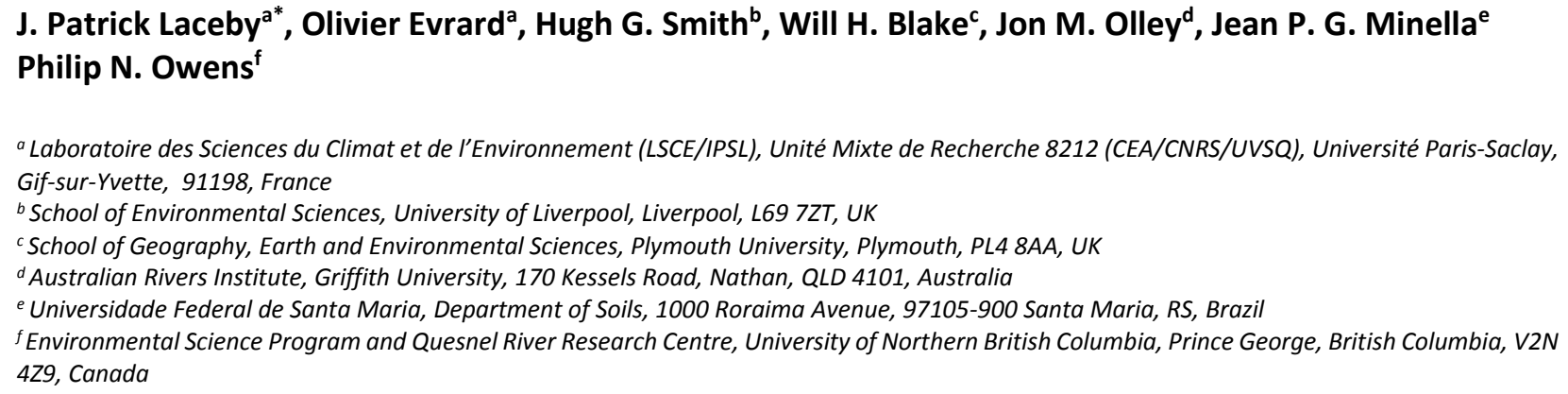

a Laboratoire des Sciences du Climat et de l'Environnement (LSCE/IPSL), Unité Mixte de Recherche 8212 (CEA/CNRS/UVSQ), Université Paris-Saclay, Gif-sur-Yvette, 91198, France

${ }^{b}$ School of Environmental Sciences, University of Liverpool, Liverpool, L69 7ZT, UK

'School of Geography, Earth and Environmental Sciences, Plymouth University, Plymouth, PL4 8AA, UK

${ }^{d}$ Australian Rivers Institute, Griffith University, 170 Kessels Road, Nathan, QLD 4101, Australia

e Universidade Federal de Santa Maria, Department of Soils, 1000 Roraima Avenue, 97105-900 Santa Maria, RS, Brazil

${ }^{f}$ Environmental Science Program and Quesnel River Research Centre, University of Northern British Columbia, Prince George, British Columbia, V2N $4 Z 9$, Canada

Abstract:

Tracing sediments back to their catchment sources using biogeochemical and physical fingerprints involves multiple assumptions. One of the most fundamental assumptions is that these fingerprints are consistent during sediment generation, transportation, and deposition processes. Accordingly, the biogeochemical fingerprints used to trace sediment must remain constant, during detachment and redistribution, or they must vary in a predictable and measurable way. One key challenge to this assumption is the sorting effect of particles by size during detachment, mobilization, transportation and deposition processes. Owing to the notable effect of particle size on sediment fingerprints, we believe it is important to review the main approaches used to address the effects of changes in particle size composition on sediment fingerprints. The two main approaches to addressing particle size impacts on fingerprint properties are: fractionation of source and sediment material to a narrow particle size range (e.g. isolation of $<10 \mu \mathrm{m}$ or $<63 \mu \mathrm{m}$ fractions), and concentration corrections (e.g. normalising concentrations by parameters such as specific surface area). These approaches are often used in combination. The utility of fractionation and corrections to address particle size effects has received increasing attention and the relative merits of these procedures have been subject to debate. Accordingly, alternative techniques to address particle size effects in sediment fingerprinting studies are being adopted. For example, a tributary tracing technique or edge-of-field samplers may minimise particle size effects on sediment source fingerprints. The interrelationships between particle size and biogeochemical tracer properties suggest that particle size may also contribute to the formation of contrasts in sediment fingerprints between sources. Indeed, there may be a significant opportunity to derive further sediment source information through comprehensively investigating and unravelling the complexity of particle size-biogeochemical interactions.

Key words: Grain size; sediment fingerprinting; composite fingerprinting; sediment tracing; sediment provenance

\author{
*Corresponding author: \\ J. Patrick Laceby \\ Phone: +330782353548 \\ Fax: +330169823568 \\ E-mail: placeby@Isce.ipsl.fr
}

43 DOI: 10.1016/j.earscirev.2017.04.009

44

Embargo: 24 months 
48 Accelerated soil erosion impacts land and water quality worldwide. Although sediment is a natural 49 component of fluvial systems that provides fundamental structure to riverine landscapes and is essential 50 in many aquatic ecosystems (Vercruysse et al., 2017; Wohl et al., 2015), the excess supply of fine sediment 51 from accelerated soil erosion often degrades riverine and coastal environments (McCulloch et al., 2003; 52 Owens et al., 2005; Walling and Collins, 2016) and contributes to the downstream transfer of particle53 bound contaminants (Gateuille et al., 2014; Yamashiki et al., 2014). Elevated suspended sediment loads 54 may also increase the cost of operating and maintaining water treatment and transportation infrastructure 55 (Clark, 1985). Knowledge of the relative contribution of different sources supplying sediment to riverine, 56 lacustrine and coastal systems is a crucial prerequisite to implementing efficient best practices necessary 57 to limit the off-site impacts of excessive sediment delivery (Belmont et al., 2011; Koiter et al., 2013b).

One increasingly adopted field-based approach to identifying sources supplying material to riverine, 59 lacustrine and coastal environments is sediment fingerprinting. Tracing sediments back to their primary 60 sources with fingerprinting techniques offers a direct method to identify the nature, location and relative 61 source contribution of sediment transported in waterways. Sediment properties such as mineral magnetic 62 parameters, fallout radionuclides, major and trace element geochemistry, and compound specific stable 63 isotopes (CSSI) have all been used to trace sediment sources (Blake et al., 2012; Caitcheon, 1993; Evrard 64 et al., 2011; Hancock and Revill, 2013; Murray et al., 1993b; Walling and Kane, 1984).

For properties to be effective tracers of sediment, they must differentiate between sediment sources whilst behaving conservatively (Walling et al., 1993). Conservative behavior is characterized by constancy in sediment properties, where the properties of sediment sources remain constant, or at the very least, any variation in these properties should occur in a predictable and measurable way. In addition, properties of the eroded sediment should remain constant through sediment detachment, transportation and deposition processes, or again, vary in a predictable and measurable way (Belmont et al., 2014; Koiter et al., 2013b; Motha et al., 2002; Olley et al., 2001).

72 Erosion and transport processes are selective regarding the particle size of the material affected. 73 Detachment processes that generate sediment for fluvial transport are particle size dependent. Clay 74 particles may resist detachment depending on the strength of their bond with the substrate whereas 75 coarse sand may resist detachment simply as a result of size and weight (Bradford et al., 1992; Poesen, 
1992). Silt and fine sand are thus more subject to detachment and subsequent transport as they are lighter and without bonds binding them to the substrate (Morgan, 2005; Poesen, 1992). Thereafter, the particle size of suspended sediment directly influences settling velocities in aquatic systems (Gibbs et al., 1971) resulting in the transport and deposition of suspended sediment being particle size selective (Viparelli et al., 2013; Walling et al., 2000). Fluvial transport, including overland flow, produces changes in the characteristics of the material being transported in comparison to the original source material. In general, the average size of particles decreases, while the degree of sorting and the average roundness increases, with distance travelled. These changes result from a combination of selective transportation, deposition, and particle abrasion, with these processes acting over the entire landscape (Frings, 2008; Krumbein and Sloss, 1951; Le et al., 2015; Moss and Walker, 1978).

Not only are sediment transport processes particle-size selective, the properties used to trace sediments may have different affinities to various particle size fractions. For example, fallout radionuclides are preferentially bound to clay minerals owing to the higher number of potential sorption sites (Fan et al., 2014; Lomenick and Tamura, 1965; Tamura, 1964). Magnetic minerals occur in soil and sediment as aggregated concretions, discrete fine grains, and particle coatings on very fine grains (Oldfield, 1991; Smith, 1999). Different geochemical elements are contained within the mineral matrix or adsorbed (Stumm and Morgan, 2012). Organic matter may coat grains or be bound within the mineral matrix (Keil and Mayer, 2014; Mayer, 1999). Ultimately, the properties used to trace sediment may have different affinities (e.g. preferential adsorption/absorption) for various particles size fractions that in combination with the selective transport of fine-grained material may affect sediment source fingerprinting results.

While there are multiple literature reviews published on sediment source fingerprinting (Collins and Walling, 2002; D'Haen et al., 2012; Davis and Fox, 2009; Guzmán et al., 2013; Haddadchi et al., 2013; Koiter et al., 2013b; Owens et al., 2016; Smith et al., 2013), and a recent emphasis on modelling approaches (Cooper et al., 2014; Haddadchi et al., 2014; Laceby and Olley, 2015; Palazón et al., 2015b; Zhang and Liu, 2016), few studies have investigated the effects of particle size on sediment source signatures (Olley and Murray, 1994; Russell et al., 2001; Smith and Blake, 2014). Here, we review the effects and challenges (section 2), approaches (sections 3 and 4) and opportunities (section 5) of particle size selectivity within the sediment source fingerprinting technique. We mainly focus on riverine environments, specifically particle size selectivity as sediment moves from hillslopes into and through river channels, but the concepts and examples presented are also relevant for similar applications in other aquatic systems such as lakes, reservoirs, estuaries and the coastal zone. 


\section{Sediment Property Predictability}

108

Sediment generation, transportation and deposition processes are known to be particle size selective, where fine particles generally have a greater probability of being detached and transported further than coarse particles (McLaren and Bowles, 1985; Walling and Moorehead, 1989). This particle size selectivity often results in potential differences in biogeochemical tracer property concentrations in detached material relative to their sources (He and Walling, 1996; Horowitz and Elrick, 1987). Accordingly, this section will review the impacts of particle size selectivity on a variety of biogeochemical properties used in sediment source fingerprinting research. We focus on some of the main properties - such as fallout radionuclides, carbon and nitrogen parameters, elemental geochemistry and mineral magnetic properties - but recognise that many of the findings are also likely to be relevant to other biogeochemical properties used as fingerprints such as colour parameters and DNA.

\subsection{Fallout Radionuclides $\left({ }^{137} \mathrm{Cs},{ }^{210} \mathrm{~Pb}\right.$ ex, $\left.{ }^{7} \mathrm{Be}\right)$}

Caesium-137 ( $\left.{ }^{137} \mathrm{Cs}, T_{1 / 2}=30 \mathrm{y}\right)$ and excess lead-210 $\left({ }^{210} \mathrm{~Pb}_{\mathrm{ex}}, T_{1 / 2}=22 \mathrm{y}\right)$ have been widely used to determine the relative contributions of sediment from different erosion processes to waterways (Ben Slimane et al., 2016; IAEA, 2014; Matisoff et al., 2002; Owens et al., 2012; Smith et al., 2011; Wallbrink et al., 1998; Walling and Woodward, 1992) (Table 1). As both ${ }^{137} \mathrm{Cs}$ and ${ }^{210} \mathrm{~Pb}$ ex are concentrated near the soil surface, as they are atmospheric fallout products, sediments eroded from rill or sheet erosion often have high ${ }^{137} \mathrm{Cs}$ and ${ }^{210} \mathrm{~Pb}_{\text {ex }}$ activity concentrations (Walling, 2005), whereas sediments eroded from subsoil channel bank or gully erosion processes have low ${ }^{137} \mathrm{Cs}$ and ${ }^{210} \mathrm{~Pb}_{\text {ex }}$ activity concentrations (Belmont et al., 2014; Olley et al., 2013; Wallbrink et al., 1999). Comparing ${ }^{137} \mathrm{Cs}$ and ${ }^{210} \mathrm{~Pb}_{\mathrm{ex}}$ in suspended sediments and sediments generated by these different erosion processes generally allows for the relative sediment contributions from these different erosion processes to be ascertained (Ben Slimane et al., 2013; Wallbrink and Murray, 1993; Wallbrink et al., 1999; Walling, 2003). 
Table 1: Examples of research utilizing only fallout radionuclides to trace sediment sources (SSA refers to specific surface area).

\begin{tabular}{|c|c|c|c|c|c|c|c|}
\hline Reference & Country & $\begin{array}{l}\text { Area } \\
\left(\mathrm{km}^{2}\right)\end{array}$ & Parameters & $\begin{array}{l}\text { Particle Size } \\
\quad(\mu \mathrm{m})\end{array}$ & $\begin{array}{c}\text { Corrections or } \\
\text { other approaches } \\
\text { to address particle } \\
\text { size dynamics }\end{array}$ & $\begin{array}{c}\text { Pre- } \\
\text { treatment } \\
\text { before } \\
\text { analysis }\end{array}$ & $\begin{array}{c}\text { Raw } \\
\text { Data } \\
\text { Availabl } \\
\text { e }\end{array}$ \\
\hline Belmont et al., 2011 & United States & 2880 & ${ }^{10} \mathrm{Be},{ }^{210} \mathrm{~Pb}_{\mathrm{ex}},{ }^{137} \mathrm{Cs}$ & $<64,<125^{a}$ & SSA & -- & Yes \\
\hline Belmont et al., 2014 & United States & 880 & ${ }^{10} \mathrm{Be},{ }^{210} \mathrm{~Pb}$ ex, ${ }^{137} \mathrm{Cs}$ & $<64,<125^{a}$ & -- & -- & Yes \\
\hline Blake et al., 2009 & Australia & $<1$ & ${ }^{7} \mathrm{Be},{ }^{210} \mathrm{~Pb}_{\mathrm{ex}},{ }^{137} \mathrm{Cs}$ & 8 fractions $^{b}$ & Enrichment factors & $\underset{c}{\text { Dispersed }}$ & Partial $^{\mathrm{d}}$ \\
\hline Bonniwell et al., 1999 & United States & 389 & ${ }^{7} \mathrm{Be},{ }^{210} \mathrm{~Pb}_{\text {ex }}{ }^{137} \mathrm{Cs}$ & -- & Ratios & -- & Yes \\
\hline Evrard et al., 2010 & Mexico & $3,9,12$ & ${ }^{7} \mathrm{Be},{ }^{210} \mathrm{~Pb}_{\mathrm{ex}},{ }^{137} \mathrm{Cs}$ & -- & Sc Comparison & -- & Partial $^{\mathrm{e}}$ \\
\hline Evrard et al., 2016 & Laos & 12 & ${ }^{7} \mathrm{Be},{ }^{210} \mathrm{~Pb}_{\mathrm{ex}},{ }^{137} \mathrm{Cs}$ & $<1000$ & Runoff samplers & -- & Yes \\
\hline Foucher et al., 2015 & France & 24 & ${ }^{137} \mathrm{Cs}$ & $\begin{array}{c}<20,20-50,50- \\
63,<2000\end{array}$ & Th correction, SSA & -- & Partial $^{\mathrm{e}}$ \\
\hline He and Owens, 1995 & United Kingdom & & ${ }^{226} \mathrm{Ra},{ }^{210} \mathrm{~Pb}$ ex,${ }^{137} \mathrm{Cs}$ & $<2000$ & SSA & -- & Yes \\
\hline Gourdin et al., 2014 & Laos & 12 & ${ }^{7} \mathrm{Be},{ }^{210} \mathrm{~Pb}_{\mathrm{ex}},{ }^{137} \mathrm{Cs}$ & $<1000$ & Ratios & -- & Partiale \\
\hline Matisoff et al., 2002 & United States & 70 & ${ }^{7} \mathrm{Be},{ }^{210} \mathrm{~Pb}_{\mathrm{ex}},{ }^{137} \mathrm{Cs}$ & -- & -- & -- & -- \\
\hline Matisoff et al., 2005 & United States & -- & ${ }^{7} \mathrm{Be},{ }^{210} \mathrm{~Pb}$ ex & -- & Ratios & -- & -- \\
\hline Murray et al., 1993a & Australia & -- & ${ }^{137} \mathrm{Cs},{ }^{226} \mathrm{Ra},{ }^{232} \mathrm{Th}$ & $<2000$ & -- & -- & -- \\
\hline Olley et al., 2013 & Australia & $47-3842$ & ${ }^{210} \mathrm{~Pb}_{\mathrm{ex}},{ }^{137} \mathrm{Cs}$ & $<10$ & -- & -- & -- \\
\hline Owens et al., 2012 & Canada & 135,215 & ${ }^{210} \mathrm{~Pb}_{\mathrm{ex}},{ }^{137} \mathrm{Cs}$ & $<63$ & SSA & -- & -- \\
\hline Smith et al., 2011 & Australia & 1.4 & ${ }^{210} \mathrm{~Pb}_{\mathrm{ex}},{ }^{137} \mathrm{Cs}$ & $<63$ & SSA & -- & Yes \\
\hline Stout et al., 2014 & United States & 4,300 & ${ }^{10} \mathrm{Be},{ }^{210} \mathrm{~Pb}_{\text {ex }},{ }^{137} \mathrm{Cs}$ & $<64,<125^{a}$ & SSA & -- & -- \\
\hline Wallbrink and Murray, 1993 & Australia & $<0.001$ & ${ }^{7} \mathrm{Be},{ }^{210} \mathrm{~Pb}$ ex,${ }^{137} \mathrm{Cs}$ & -- & -- & -- & -- \\
\hline Wallbrink et al., 1998 & Australia & 13500 & ${ }^{210} \mathrm{~Pb}$ ex,${ }^{137} \mathrm{Cs}$ & $<2^{a}$ & -- & -- & -- \\
\hline $\begin{array}{l}\text { Walling and Woodward, } \\
1992\end{array}$ & United Kingdom & 12,46 & ${ }^{7} \mathrm{Be},{ }^{210} \mathrm{~Pb}$ ex,${ }^{137} \mathrm{Cs}$ & $<63$ & Source correction & -- & -- \\
\hline
\end{tabular}


Although they have been used for tracing sediment generated from erosion processes (Wallbrink and Murray, 1996b), beryllium-7 ( $\left.{ }^{7} \mathrm{Be}, T_{1 / 2}=53 \mathrm{~d}\right)$ and ${ }^{210} \mathrm{~Pb}_{\text {ex }}$ are also increasingly used as chronometers of

134 sediment transfers in riverine systems (Bonniwell et al., 1999; Evrard et al., 2016; Gourdin et al., 2014; 135 Mabit et al., 2014; Smith et al., 2014; Taylor et al., 2013). For example, these radionuclides quantify the relative sediment contribution from 'old' ('Be-depleted) and 'new' ('Be-enriched) sources (Evrard et al., 2010; Matisoff et al., 2005). Over longer time scales, additional tracers are capable of providing further chronological information (e.g. ${ }^{10} \mathrm{Be}, T_{1 / 2}=1.39 \times 10^{6}$ y) (Belmont et al., 2011; Stout et al., 2014). In particular, Belmont et al. (2014) combined ${ }^{10} \mathrm{Be},{ }^{210} \mathrm{~Pb}_{\mathrm{ex}}$ and ${ }^{137} \mathrm{Cs}$ measurements to demonstrate the potential for over-estimating channel source contributions when there is a moderate amount of sediment exchange between the channel and the floodplain in large watersheds over sediment routing timescales.

Research has demonstrated that fallout radionuclides are typically enriched in the fine particle size fractions. For example, He and Walling (1996) reported increasing activity concentrations of ${ }^{137} \mathrm{Cs}$ and ${ }^{210} \mathrm{~Pb}_{\text {ex }}$ with increasing specific surface area (SSA) (Figure 1). SSA is closely related to particle size (Horowitz, 1991) and is reported as the total surface area per unit mass (Rawlins et al., 2010). For example, the SSA of sediment increases with decreasing particle size to the extent that the SSA values for clays may be several orders of magnitude greater than silt and sand (Walling and Moorehead, 1989). As fallout radionuclides are preferentially bound to clay minerals owing to the higher number of potential sorption sites (Fan et al., 2014; Lomenick and Tamura, 1965; Tamura, 1964), activity concentrations typically increase with increasing SSA and decreasing particle size (He and Owens, 1995; Wallbrink et al., 1999). Although less research has documented the relationship between particle size and ${ }^{7} \mathrm{Be}$, this fallout radionuclide has also been found to be enriched in fine particle size fractions (Blake et al., 2009; Taylor et al., 2014; Wallbrink and Murray, 1996a). As fallout radionuclides are typically enriched in fine particle size fractions, it may be possible to quantify their relationship with SSA.

The challenge is that there are exceptions to the rule. For example, Smith and Blake (2014) observed that

${ }^{137} \mathrm{Cs}$ and ${ }^{210} \mathrm{~Pb}_{\text {ex }}$ were negatively related to SSA in pasture soils ( $p<0.05$ for ${ }^{210} \mathrm{~Pb}_{\text {ex }}$ only), whereas they exhibited positive though non-significant relationships with SSA in channel bank and cultivated soils. This highlights the fact that although these fallout radionuclides are generally enriched in the fine particle size 159 fractions, there may be exceptions, and individual sources may behave differently. Potential exceptions may be explained by the presence and amount of $\mathrm{HCl}$-extractable materials, which Singleton et al. (2017) reported to have a stronger control on fallout radionuclides than grain size or mineralogy. Furthermore, 
fallout and subsequent diffusion and migration processes (Jagercikova et al., 2015). Therefore, fallout radionuclide activity concentrations may decrease with soil depth despite increasing clay content as deeper soil was not exposed to fallout. These exceptions demonstrate the need to understand the relationship between particle size distribution and the tracer property of interest in each study.

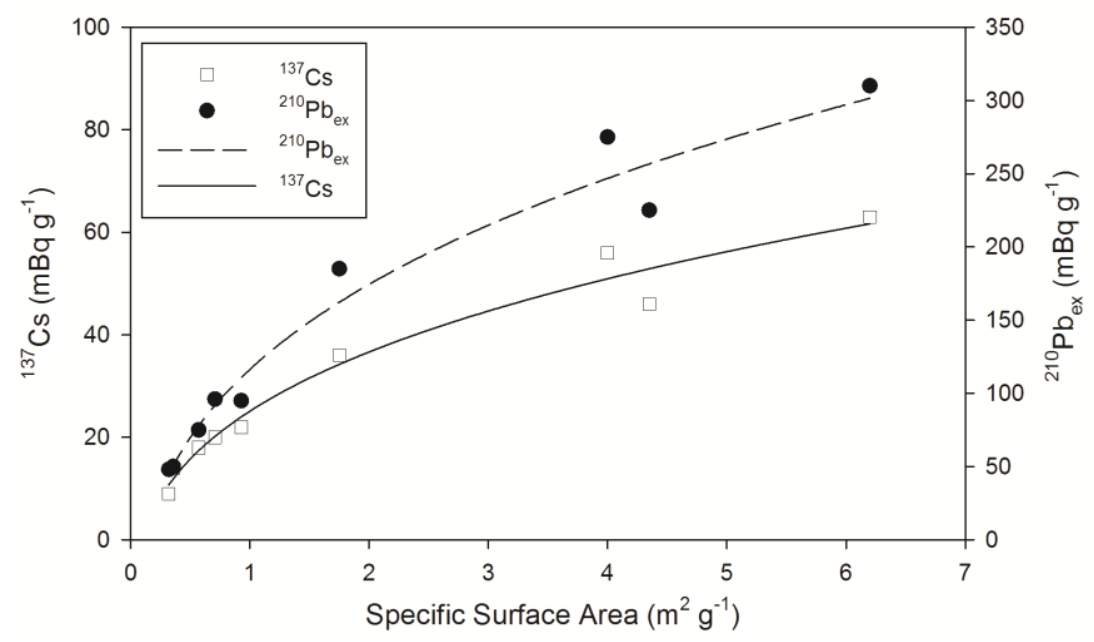

Figure 1: Relationship between specific surface area and fallout radionuclide activity concentrations $\left({ }^{137} \mathrm{Cs}\right.$ and ${ }^{210} \mathrm{~Pb}$ ex) (adaptation of Figure 1 from He and Walling (1996)).

\subsection{Carbon and Nitrogen Parameters}

Although they are not as extensively analyzed in sediment tracing research as fallout radionuclides, carbon and nitrogen parameters provide an interesting example into tracer property relationships with particle size. Total organic carbon (TOC) and total nitrogen (TN) often discriminate between sediment derived from surface and subsoil erosion processes as their concentration decreases with depth in the soil profile (Blake et al., 2006; Owens et al., 2006). Carbon stable isotopes $\left(\delta^{13} \mathrm{C}\right)$ may potentially discriminate between sediment derived from soils with $\mathrm{C}_{3}$ vegetation (majority of tree or temperate grass species) compared to those covered with $C_{4}$ vegetation (grass and cropping species typically under warmer climates) (Fry, 2006; Schimel, 1993). Source discrimination with nitrogen stable isotopes $\left(\delta^{15} \mathrm{~N}\right)$ is more complex. In general, soil $\delta^{15} \mathrm{~N}$ increases with depth in soil profiles (Amundson et al., 2003; Natelhoffer and Fry, 1988). Other factors such as nitrogen inputs from animal and human waste, along with fertilizers and potentially topographic position, may impact the predictability of $\delta^{15} \mathrm{~N}$ in a tracing context. Of note, these parameters trace organic matter (Garzon-Garcia et al., 2017; Olley, 2002) and therefore they may be fractionated by density as well as particle size. Furthermore, these parameters also have the potential for non-conservative behavior due to biological uptake and consumption. Nonetheless, these parameters are increasingly used in sediment 
tracing research (Fox and Papanicolaou, 2007; Laceby et al., 2015b; Mukundan et al., 2010; Papanicolaou et al., 2003) (Table 2).

Similarly to fallout radionuclides, TOC and TN are generally enriched in the fine particle size fraction (Balesdent et al., 1987; Wynn et al., 2005). For example, when normalizing the $<2,<10$, and $<63 \mu \mathrm{m}$ fractions by the bulk soil ( $<2 \mathrm{~mm}$ ) fraction, Laceby et al. (2015b) reported that the $<63 \mu \mathrm{m}$ fraction was significantly different than the $<2$ and $<10 \mu \mathrm{m}$ fractions for TN, though not for TOC, indicating that these similar properties may behave slightly differently in two Australian catchments (Figure 2). Laceby et al.

192 (2016) also reported significant enrichment for TOC and TN between the bulk soil and the $<63 \mu \mathrm{m}$ fraction

193 for subsoils and cultivated sources, though not for forest source samples in several Japanese catchments 194 (Figure 3).

195 More variability is anticipated in the relationship between particle size and $\delta^{15} \mathrm{~N}$ and $\delta^{13} \mathrm{C}$ (Balesdent et al., 196 1987; Bellanger et al., 2004). However, Laceby et al. (2015b) reported that there were not significant 197 differences between particle size fractions for $\delta^{15} \mathrm{~N}$, with very limited $\delta^{13} \mathrm{C}$ variation across different 198 particle size fractions (Figure 2). Similarly, Laceby et al. (2016) found little variation between the bulk soil 199 fraction and the $<63 \mu \mathrm{m}$ fraction for $\delta^{13} \mathrm{C}$, with increasing, though not significant, enrichment for $\delta^{15} \mathrm{~N}$ 200 (Figure 3).

201 Based on the fundamental principles of sediment source fingerprinting, as long as the enrichment is 202 predictable, these organic sediment properties could potentially be effective tracers of erosion processes, 203 particularly in contexts where fallout radionuclides are ineffective. $\delta^{15} \mathrm{~N}$ appears more complex and may 204 be enriched or depleted in the different particle size fractions, which requires investigation on a case by 205 case basis. $\delta^{13} \mathrm{C}$ apparently behaves very predictably in a sediment tracing context although there will likely 206 be exceptions. Importantly, the particle size enrichment for TOC, TN and $\delta^{15} \mathrm{~N}$ varied for the individual 207 sources (Laceby et al., 2016). Therefore, it is crucial to understand the predictability of particle size effects 208 when tracing sediment sources with these and other carbon and nitrogen properties (e.g. compound 209 specific stable isotopes (Reiffarth et al., 2016)). 
Table 2: Examples of research using only carbon $(C)$ and nitrogen $(N)$ parameters to trace sediment sources

\begin{tabular}{|c|c|c|c|c|c|c|c|}
\hline Reference & Country & Area $\left(\mathrm{km}^{2}\right)$ & Parameters & $\begin{array}{l}\text { Particle Size } \\
(\mu \mathrm{m})\end{array}$ & $\begin{array}{c}\text { Corrections or } \\
\text { other } \\
\text { approaches } \\
\text { to address } \\
\text { particle size } \\
\text { dynamics }\end{array}$ & $\begin{array}{c}\text { Pre- } \\
\text { treatment } \\
\text { before } \\
\text { analysis }\end{array}$ & $\begin{array}{c}\text { Raw } \\
\text { Data } \\
\text { Availabl } \\
\text { e }\end{array}$ \\
\hline Fox and Papanicolaou, 2007 & United States & 0.71 & $\delta^{13} \mathrm{C}, \delta^{15} \mathrm{~N}, \mathrm{C} / \mathrm{N}$ & $<53$ & -- & Dispersed & Yes \\
\hline Garzon-Garcia et al., 2017 & Australia & $2.5,75,3076$ & $\delta^{13} \mathrm{C}, \delta^{15} \mathrm{~N}, \mathrm{TOC}, \mathrm{TN}$ & $<10,<63,<500$ & -- & -- & Yes \\
\hline Gibbs, 2008 & New Zealand & 117 & CSSI & $<1000$ & -- & -- & Yes \\
\hline Hancock and Revill, 2013 & Australia & 3860 & CSSI & $<63$ & -- & -- & -- \\
\hline Laceby et al., 2015b & Australia & $75,123,311$ & $\delta^{13} \mathrm{C}, \delta^{15} \mathrm{~N}, \mathrm{TOC}, \mathrm{TN}$ & $<2,<10,<63,<2000$ & -- & -- & -- \\
\hline Laceby et al., 2016 & Japan & $77,171,265$ & $\delta^{13} \mathrm{C}, \delta^{15} \mathrm{~N}, \mathrm{TOC}, \mathrm{TN}$ & $<63,<2000$ & -- & -- & Yes \\
\hline Olley, 2002 & Australia & 84000 & $\delta^{13} \mathrm{C}, \mathrm{C} / \mathrm{N}$ Ratio & $<2$ & -- & -- & -- \\
\hline Papanicolaou et al., 2003 & United States & 600 & $\delta^{13} \mathrm{C}, \delta^{15} \mathrm{~N}, \mathrm{C} / \mathrm{N}$ & -- & -- & -- & -- \\
\hline
\end{tabular}



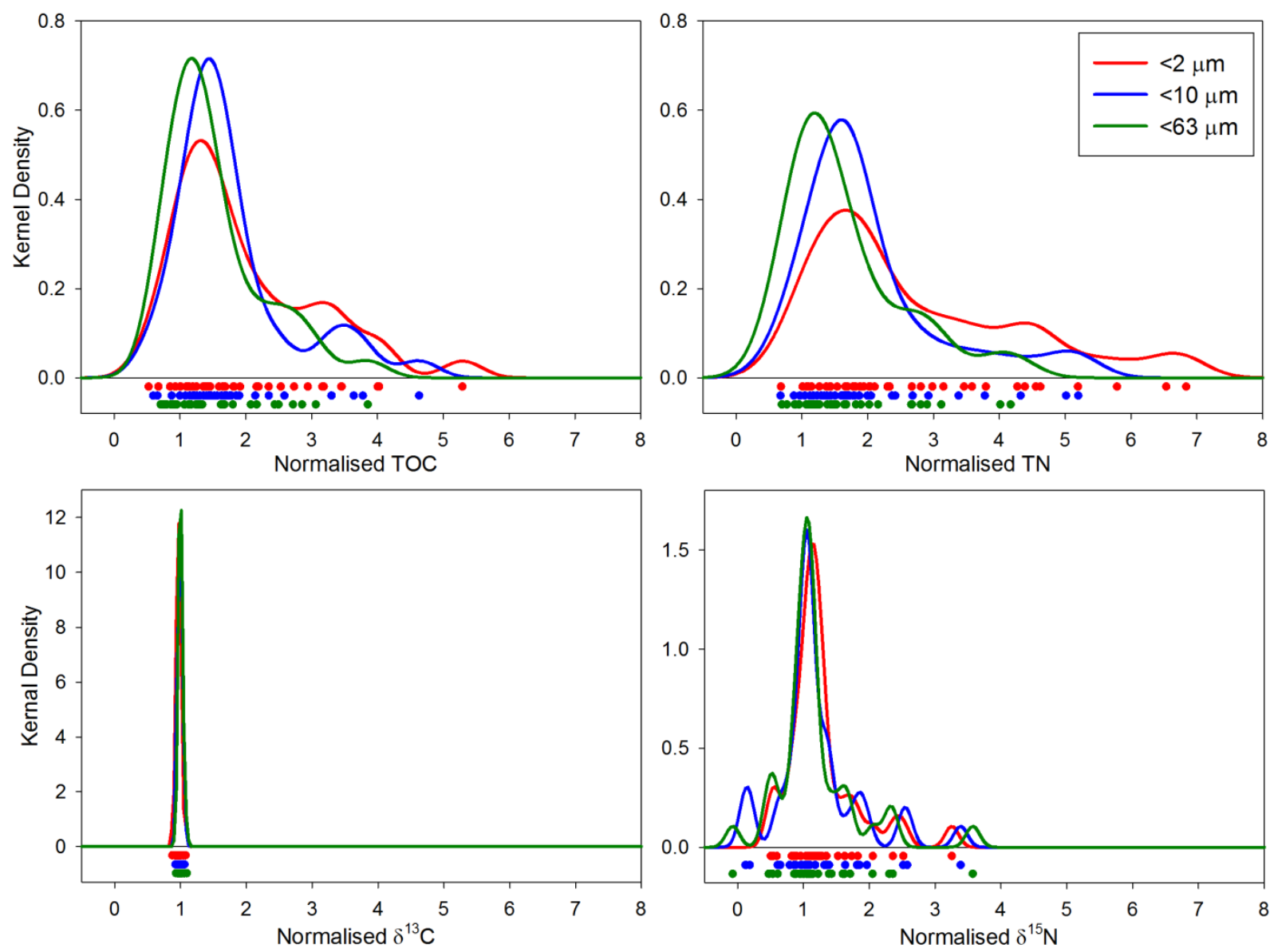

Figure 2: Normalized carbon (C) and nitrogen (N) property distributions for the $<2 \mu \mathrm{m},<10 \mu \mathrm{m}$ and $<63$ $\mu \mathrm{m}$ particle size fractions in samples from Knapp Creek and Blackfellow Creek, Australia (modified from Laceby et al., (2015b)). Points under the distributions are the normalized samples color coded to particle size fraction used to derive these distributions with kernel density functions. 

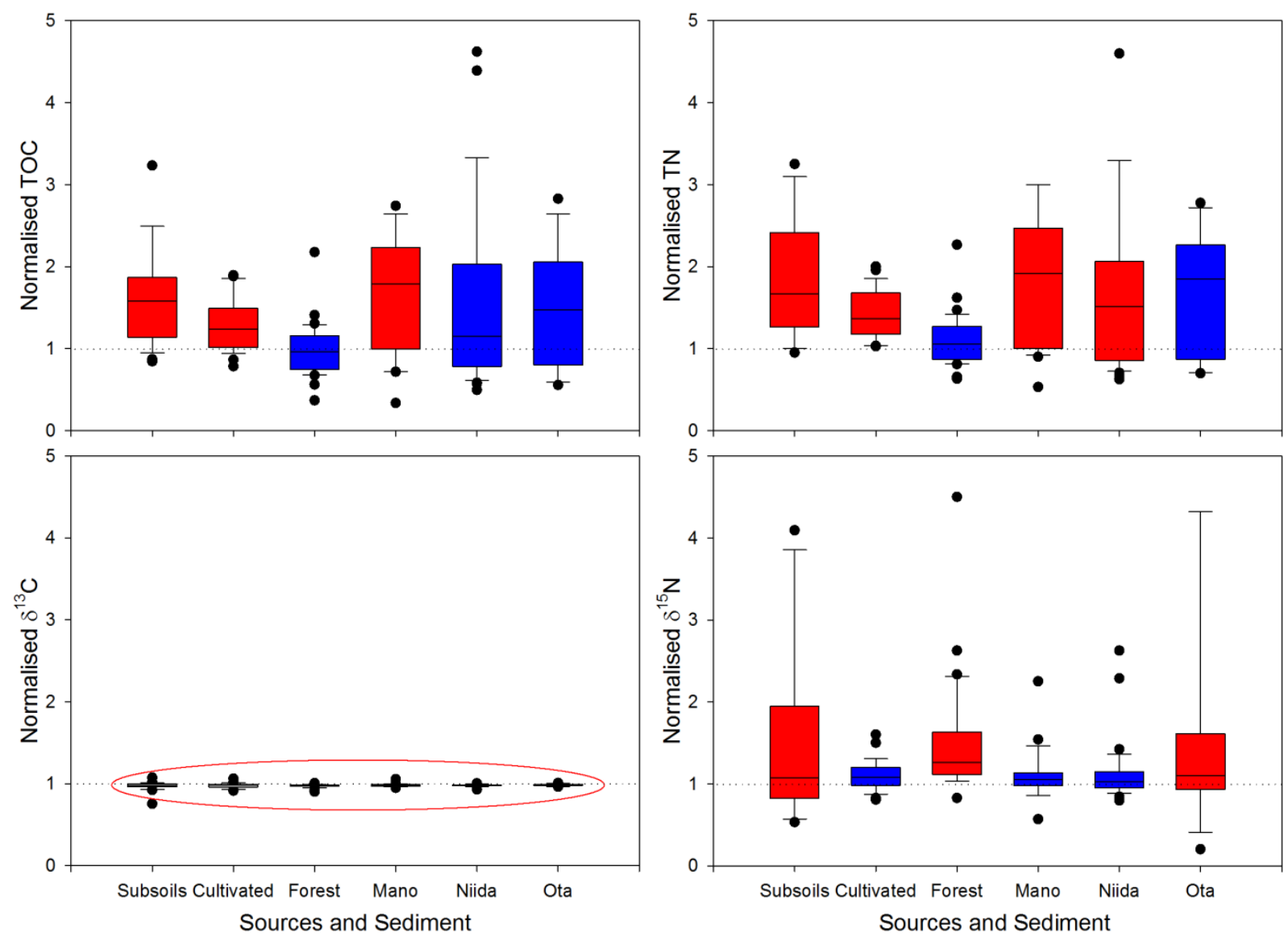

Figure 3: Box plots of the normalized difference between carbon (C) and nitrogen (N) sediment properties in the $<63 \mu \mathrm{m}$ fraction divided by the $<2 \mathrm{~mm}$ fraction for the three sources and sediment from three Japanese catchments (i.e., Mano, Niida and Ota) with red shading (and the red circle) indicating significant differences between the two fractions and values greater than 1 (the dotted line) being enriched in the $<63 \mu \mathrm{m}$ fraction (modified from Laceby et al., (2016)).

\subsection{Elemental Geochemistry}

214 Major and trace elemental geochemistry (including rare earth elements) are often used to identify the

215 different spatial sources of sediment (Hardy et al., 2010; Laceby and Olley, 2015; Vale et al., 2016) (Table

216 3). Different parent rock material typically results in sources having distinct elemental geochemistry

217 (Douglas et al., 2009; Motha et al., 2002; Olley et al., 2001). Eroded sediment often maintain these

218 geochemical fingerprints, allowing the relative contributions of different sources to be ascertained

219 (Caitcheon et al., 2006; D'Haen et al., 2013; Hughes et al., 2009). The question is whether these fingerprints

220 are conservative during sediment generation, transportation and deposition processes.

221 The relationship between particle size enrichment and elemental geochemistry is complex and partly

222 dependent on the digestion procedure (e.g. acid leached versus total digestion) used to prepare samples 
223 for analysis (e.g. inductively coupled plasma mass spectrometry (ICP-MS)). The difficulty is that elemental 224 analyses often provide results for over 40 elements (Table 3 ) whereas the previous sections examined 225 three fallout radionuclides and four carbon and nitrogen parameters. For each of these 40 plus elements, 226 sediment generation, transport and deposition processes may potentially enrich their elemental 227 concentrations, deplete them, or have a limited impact (e.g. Motha et al., 2002; Russell et al., 2001; Smith 228 and Blake, 2014). The impact of particle size selectivity on elemental geochemistry likely will depend on 229 how elements are incorporated into fine sediment (e.g. within the mineral matrix or adsorbed).

230 Underlying the potential influence of particle size on elemental geochemistry is the effect of sediment 231 source mineralogy. The dominant mineralogy relates directly to particle size where some sources will be 232 enriched in the fine particle size fractions and other sources may be depleted. Thus the geochemical 233 fingerprint likely will change if the $<2 \mathrm{~mm}$, the $<63 \mu \mathrm{m}$, or the $<10 \mu \mathrm{m}$ fraction are sampled and analysed. 234 For example, each of the three different sources in Figure 4 from Gibbs (1967) may have different 235 relationships between elemental concentrations and particle size, which will depend on the particle size 236 range utilized for the sediment source fingerprinting research. Fundamentally, the impact of particle size 237 on all elemental concentrations for each source is difficult to predict and the complexity of the particle 238 size - elemental geochemistry relationship requires more research to comprehensively characterize the 239 predictability of these fingerprints. Accordingly, section 4 of this review provides several 240 recommendations for addressing particle size in sediment source fingerprinting research. 
Table 3: Examples of sediment tracing research using only elemental geochemistry (e.g. major, trace and rare earth elements).

\begin{tabular}{|c|c|c|c|c|c|c|c|}
\hline Reference & Country & Area $\left(\mathrm{km}^{2}\right)$ & $\begin{array}{l}\text { Elements } \\
\text { Analyzed } \\
(n)\end{array}$ & $\begin{array}{l}\text { Particle Size } \\
(\mu \mathrm{m})\end{array}$ & $\begin{array}{l}\text { Corrections or other } \\
\text { approaches to } \\
\text { address particle size } \\
\text { dynamics }\end{array}$ & $\begin{array}{l}\text { Pre- } \\
\text { treatment } \\
\text { before } \\
\text { analysis }\end{array}$ & $\begin{array}{l}\text { Raw Data } \\
\text { Available }\end{array}$ \\
\hline Cooper et al., 2015 & United Kingdom & 5 & 11 & $<63$ & -- & Dispersed $^{a}$ & -- \\
\hline D'Haen et al., 2013 & Turkey & 264 & 18 & $<63$ & -- & Dispersed $^{b}$ & -- \\
\hline Douglas et al., 2003 & Australia & 22000 & 50 & $<10$ & -- & -- & -- \\
\hline Haddadchi et al., 2015 & Australia & 911 & 41 & $<10,10-63,63-212$ & -- & -- & -- \\
\hline Hardy et al., 2010 & Canada & 12000 & 55 & $63-250$ & Density separation & -- & -- \\
\hline Laceby et al., 2015a & Australia & 74 & 37 & $<10$ & -- & -- & -- \\
\hline Laceby and Olley, 2015 & Australia & $75,123,311$ & 23 & $<10$ & -- & -- & -- \\
\hline $\begin{array}{l}\text { Olley and Caitcheon } \\
2000\end{array}$ & Australia & 650000 & 10 & $<10$ & -- & Dispersed ${ }^{\mathrm{c}}$ & Partial $^{\mathrm{d}}$ \\
\hline Vale et al., 2016 & New Zealand & 5870 & 44 & $<63$ & -- & -- & -- \\
\hline
\end{tabular}

241 a Source samples sonified before sieving

242 bSamples were boiled in distilled water to disperse soil aggregates

243 ' Samples sonified before settling in a water column

$244 \quad$ Raw data is only available for sediment core samples 


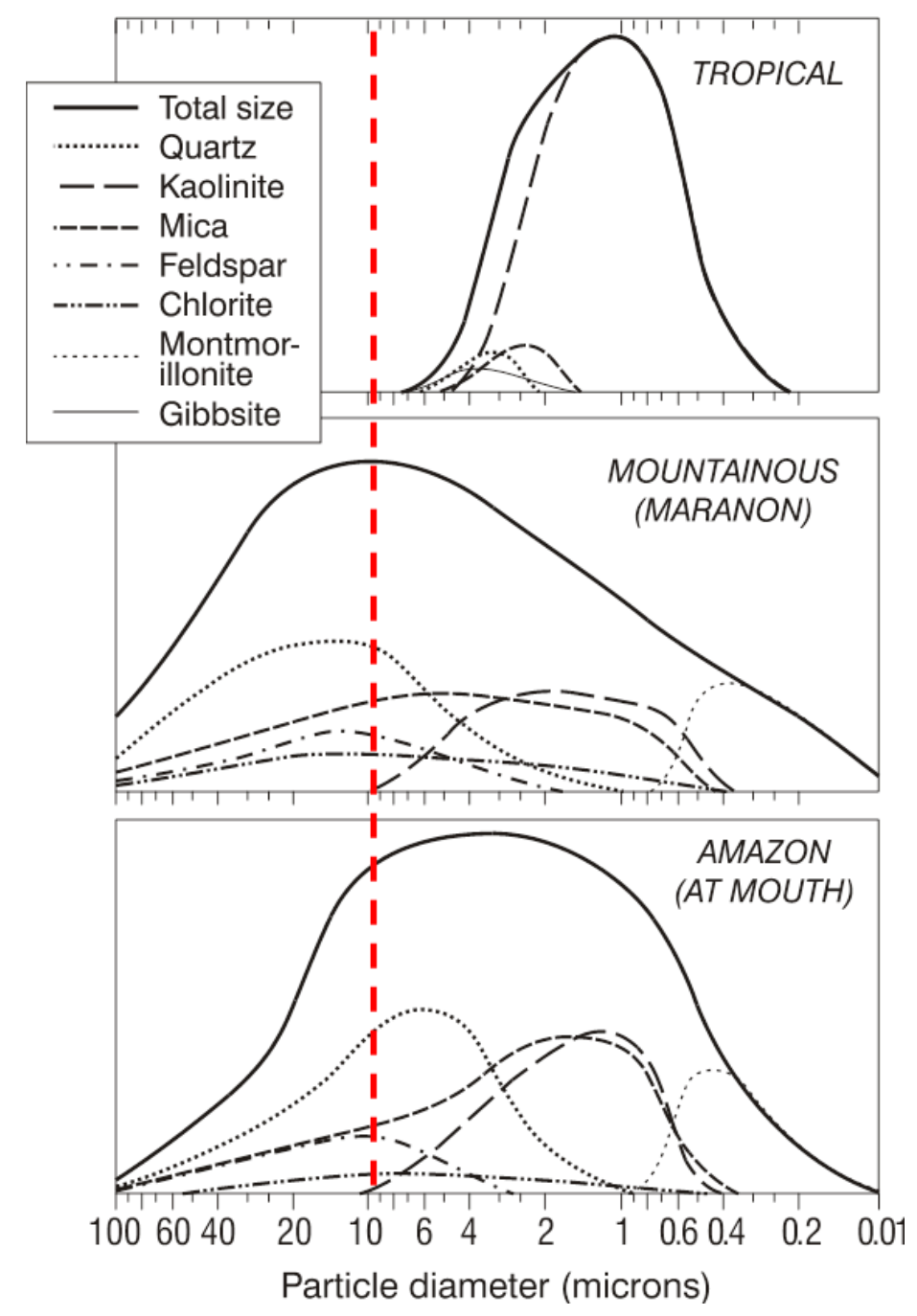

Figure 4: Changes in mineralogy with particle size in sediment from three locations in the Amazon basin from Gibbs (1967) with the red dashed line added to indicate the impact of fractionating the samples at the $<10 \mu \mathrm{m}$ particle size. 


\subsection{Mineral Magnetic Properties}

247 Mineral magnetic properties (e.g. magnetic susceptibility, isothermal remanent magnetisation) have also 248 been widely used to investigate sediment provenance (Blake et al., 2004; Palazón et al., 2015a; Pulley et 249 al., 2015b; Walling et al., 1979) (Table 4). The signatures derived from magnetic minerals may be classified 250 as primary (i.e. from parent material prior to weathering) or secondary (i.e. from chemical processes and 251 other processes and effects) (Hatfield, 2014). As the signature is often derived from parent material, 252 mineral magnetic properties can trace sediment derived from different spatial sources (Caitcheon, 1993). 253 Owing to the potential impact of secondary processes, such as anthropogenic inputs and diagenetic 254 processes, mineral magnetic properties may also provide further source discrimination between different 255 erosion processes (Foster et al., 1998; Pulley et al., 2015b).

256 Magnetic minerals occur in soil and sediment as aggregated concretions, discrete fine grains and particle 257 coatings on very fine grains (Oldfield, 1991; Smith, 1999). Accordingly, mineral magnetic properties may 258 be highly dependent on particle size (Foster et al., 1998; Oldfield et al., 1985). In particular, Hatfield and 259 Maher (2008) demonstrated the importance of characterizing mineral magnetic properties with a particle260 size specific approach as different magnetic properties were preferentially associated with different 261 particle size fractions. These authors demonstrated that bacterial magnetosomes formed in lake sediment 262 in the $<2 \mu \mathrm{m}$ and the 2-8 $\mu \mathrm{m}$ fractions. Accordingly, they only quantified source contributions to the 8-31 $263 \mu \mathrm{m}$ and 31-63 $\mu \mathrm{m}$ fractions. In contrast, Pulley et al. (2015b) reported significantly different magnetic 264 properties in the $<32 \mu \mathrm{m}$ and the $>32 \mu \mathrm{m}$ fractions and, for Caitcheon (1998), the 63-125 $\mu \mathrm{m}$ fraction was 265 appropriate for tracing tributary source contributions.

266 The challenge is that the particle size fraction driving the mineral magnetic signature may vary for each 267 catchment. For example, the sand and silt fractions may be the most appropriate particle size in 268 catchments in England to quantify sediment sources with magnetic fingerprinting techniques as these 269 fractions have been found to contribute a significant proportion of the mineral magnetic signature 270 (Hatfield and Maher, 2009). Conversely, high magnetic parameters were found in the clay-size particles in 271 the eastern United States (Oldfield et al., 1985). In South Africa, the impact of particle size on mineral 272 magnetic properties was found to be limited in the $>32 \mu \mathrm{m}$ fraction (Pulley et al., 2015b). 
Table 4: Examples of sediment source fingerprinting research with only mineral magnetic analyses

\begin{tabular}{|c|c|c|c|c|c|c|c|}
\hline Reference & Country & Area $\left(\mathrm{km}^{2}\right)$ & $\begin{array}{c}\text { Magnetic } \\
\text { Parameters } \\
\text { (n) }\end{array}$ & $\begin{array}{c}\text { Particle Size } \\
(\mu \mathrm{m})\end{array}$ & $\begin{array}{l}\text { Corrections or other } \\
\text { approaches to } \\
\text { address particle size } \\
\text { dynamics }\end{array}$ & $\begin{array}{l}\text { Pre- } \\
\text { treatment } \\
\text { before } \\
\text { analysis }\end{array}$ & $\begin{array}{c}\text { Raw } \\
\text { Data } \\
\text { Available }\end{array}$ \\
\hline Blake et al., 2004 & Australia & 446 & 9 & $<10$ & -- & -- & Yes \\
\hline Caitcheon, 1993 & Australia & 22 & 2 & 7 fractions $^{\mathrm{a}}$ & Density separation & -- & -- \\
\hline Foster et al., 1998 & United Kingdom & $1.5,12$ & 10 & 11 fractions $^{b}$ & -- & Dispersed $^{c}$ & -- \\
\hline Hatfield and Mayer, 2009 & United Kingdom & 240 & 10 & $<2,2-8,8-31,31-63,>63$ & -- & Dispersed $^{d}$ & -- \\
\hline Oldfield et al., 1985 & United States & 33 & 7 & 10 fractions $^{\mathrm{e}}$ & -- & Dispersed $^{f}$ & -- \\
\hline Pulley et al., 2015b & South Africa & $148-5751$ & 6 & 7 fractions $^{\mathrm{g}}$ & -- & Dispersed ${ }^{\text {h }}$ & -- \\
\hline Slattery et al., 1995 & United Kingdom & 6 & 4 & $<2,2-16,16-63$ & Source correction ${ }^{i}$ & Dispersed $^{j}$ & -- \\
\hline Walling et al., 1979 & United Kingdom & 12 & 5 & -- & -- & -- & -- \\
\hline $\begin{array}{l}7 \text { particle size fractions analyzed: }< \\
\text { o Sediment cores: no fractionation, s } \\
\text { c Calgon before dry-sieving to } 4 \phi \text { an } \\
\text { d Fractionated samples were disperse } \\
\text { e } 10 \text { fractions analyzed ( } 1-10 \phi) \\
\text { f Dispersed with Calgon } \\
\text { S }<32,32-63,63-125,125-250,250-5 \\
\text { Dispersed with sonification } \\
\text { Corrected to a standard particle size } \\
\text { Dispersal method not provided }\end{array}$ & $\begin{array}{l}63-125,125-250,250- \\
\text { ace soils: }<63 \mu \mathrm{m} \text {, soil } \\
\text { or }<4 \text { \$ sodium hexam } \\
\text { with Calgon prior to so }\end{array}$ & $\begin{array}{l}\text { o, } 500-1400,14 \\
\text { res: }<2000 \mu \mathrm{m}, \mathrm{a} \\
\text { aphosphate and } \\
\text { fication }\end{array}$ & $\begin{array}{l}2000 \mu \mathrm{m} \\
\text { one bulk sedimen } \\
\text { hydrous } \mathrm{Na}_{2} \mathrm{CO}_{3} \text { fo }\end{array}$ & $\begin{array}{l}\text { mples split into } 11 \text { fractions } \\
\text { e bulk sample split into } 11 \text { fraction }\end{array}$ & & & \\
\hline
\end{tabular}


275 The challenge for mineral magnetic properties, and other sediment fingerprints, is that these properties

276 are related to particle size and this relationship varies from catchment to catchment, subcatchment to

277 subcatchment, and even potentially from event to event. Further, these sediment properties are not only

278 sensitive to changes in their sources, they are also sensitive to changes in sediment transport processes

279 that may impact the potential abundance and availability of the different particle size fractions over a

280 range of spatial temporal scales (Hatfield, 2014).

\subsection{Composite Fingerprinting Approach}

282 Peart and Walling (1986) advocated for multiple parameters to be used when quantifying sediment source 283 dynamics in order to improve the overall consistency and reliability of source ascription results. The 284 combination of multiple parameters creates a composite fingerprint (Walling et al., 1993) that allows for 285 an increased number of sources to be modelled and is theorized to be more representative of the linkages 286 between sediments and their sources, potentially reducing false matches which were hypothesized to 287 potentially occur with individual tracer properties (Collins et al., 1996). Accordingly, a composite 288 fingerprinting approach has been broadly applied in sediment source fingerprinting research combining 289 several or all of the following: fallout radionuclides, carbon and nitrogen parameters, element 290 geochemistry, mineral magnetics and other parameters, thereby providing significant source 291 discrimination (Collins et al., 1996; Evrard et al., 2013; Navratil et al., 2012; Owens et al., 2000) (Table 5). 292 One challenge with the composite fingerprinting approach is that each of the potential complexities within 293 the particle size - tracer parameter relationship described above is integrated into the expanded 294 composite fingerprint. A second challenge is that it is difficult, if not impossible, to link outputs of 295 statistical-based approaches (e.g. composite fingerprinting) back to a process-based understanding of 296 sediment dynamics. 
Table 5: Examples of sediment source fingerprinting research using a composite fingerprinting approach incorporating two or more of types of biogeochemical parameters with geochemistry (Geochem), mineral magnetics (Mags), radionuclides (RN), clay mineralogy (Clay min.), diffuse reflectance infrared Fourier transform spectrometry (DRIFTS), X-ray Diffraction (XRD) and other tracers as listed.

\begin{tabular}{|c|c|c|c|c|c|c|c|}
\hline Reference & Country & Area $\left(\mathrm{km}^{2}\right)$ & Parameters & $\begin{array}{l}\text { Particle Size } \\
(\mu \mathrm{m})\end{array}$ & $\begin{array}{l}\text { Corrections or other } \\
\text { approaches to address } \\
\text { particle size dynamics }\end{array}$ & $\begin{array}{l}\text { Pre- } \\
\text { treatment } \\
\text { before } \\
\text { analysis }\end{array}$ & $\begin{array}{l}\text { Raw Data } \\
\text { Available }\end{array}$ \\
\hline Ben Slimane et al., 2013 & Tunisia & 2.6 & $\mathrm{RN}, \mathrm{C}, \mathrm{N}$ & $<2000$ & SSA & -- & -- \\
\hline Ben Slimane et al., 2016 & Tunisia & $0.6-4$ & $\mathrm{RN}, \mathrm{C}$ & $<2000$ & SSA & -- & -- \\
\hline Blake et al., 2006 & Borneo & $<2$ & Geochem, N & $<125$ & -- & -- & -- \\
\hline Blake et al., 2012 & United Kingdom & 1.5 & CSSI, Geochem, Mags & $<63$ & $\mathrm{SSA}^{\mathrm{a}}$ & -- & -- \\
\hline Caitcheon et al., 2006 & Australia & 9051 & Geochem, RN & $<10$ & -- & -- & Partial $^{b}$ \\
\hline Collins et al., 1996 & United Kingdom & 601,4325 & Geochem, RN, C,N & -- & SSA & -- & -- \\
\hline Devereux et al., 2010 & United States & 188 & Geochem, RN, C & $<63$ & -- & -- & -- \\
\hline Douglas et al., 2009 & Australia & 638 & Geochem, RN & $<10$ & -- & -- & -- \\
\hline Douglas et al., 2006a & Australia & 144000 & Geochem, Clay Min. & $<10$ & -- & -- & -- \\
\hline Douglas et al., 2006b & Australia & 144000 & Geochem, Clay Min. & $<10$ & -- & -- & -- \\
\hline Evrard et al., 2011 & France & 907 & Geochem, RN & $<2000$ & Sc comparison & -- & Partial $^{c}$ \\
\hline Evrard et al., 2013 & Mexico & $3,9,12,630$ & $\begin{array}{c}\text { Geochem, RN, DRIFTS, C, } \\
\text { N, } \delta^{13} \mathrm{C}\end{array}$ & $<250$ & $\mathrm{~d}_{50}$ comparison & -- & Partiall $^{\mathrm{c}}$ \\
\hline $\begin{array}{l}\text { Hatfield and Mayer, } \\
2008\end{array}$ & United Kingdom & 240 & Geochem, Mags & $\begin{array}{c}<2,2-8,8-31 \\
31-63\end{array}$ & -- & Dispersed $^{d}$ & -- \\
\hline Hughes et al., 2009 & Australia & 6000 & Geochem, RN & $<10$ & -- & -- & -- \\
\hline Koiter et al., 2013b & Canada & 74 & Geochem, RN & $<2000$ & -- & -- & -- \\
\hline Le Gall et al., 2016 & France & 24 & $\begin{array}{c}\text { Geochem, RN, Sr } \\
\text { Isotopes }\end{array}$ & $<63,<2000$ & Th-correction & -- & Yes \\
\hline $\begin{array}{l}\text { Martínez-Carreras et } \\
\text { al., } 2010\end{array}$ & Luxembourg & $0.7,3,4$ & $\begin{array}{c}\text { Geochem, RN, Colour, C, } \\
\text { N, P }\end{array}$ & $<63$ & -- & -- & -- \\
\hline Minella et al., 2008 & Brazil & 1.2 & Geochem, C & $<150$ & -- & -- & -- \\
\hline Motha et al., 2002 & Australia & 110 & Geochem, RN, Mags & $\begin{array}{c}<2,2-20,20- \\
40,40-63\end{array}$ & Source correction ${ }^{\mathrm{e}}$ & Dispersed $^{f}$ & -- \\
\hline Motha et al., 2003 & Australia & 65 & Geochem, RN & $\begin{array}{c}<2,2-20,20- \\
40,40-63\end{array}$ & Source correction ${ }^{\mathrm{e}}$ & Dispersed $^{f}$ & -- \\
\hline Mukandan et al., 2010 & United States & 182 & Geochem, RN, $\delta^{15} \mathrm{~N}, \mathrm{C}, \mathrm{N}$ & $<2000$ & Texture comparison & -- & -- \\
\hline
\end{tabular}




\begin{tabular}{|c|c|c|c|c|c|c|c|}
\hline Navratil et al., 2012 & France & 905 & Geochem, RN & $<63$ & -- & -- & Partial $^{\mathrm{C}}$ \\
\hline Owens et al., 2000 & United Kingdom & 4390 & $\begin{array}{c}\text { Geochem, RN, Mags, C, } \\
\text { N }\end{array}$ & $<63$ & SSA & Dispersed $^{d}$ & -- \\
\hline Owens et al., 2006 & Canada & 135,215 & Geochem, Mags, C, N & $<500$ & -- & -- & -- \\
\hline Palazon et al., 2015a & Spain & 1509 & Geochem, Mags, RN, C & $<63$ & -- & -- & Partial $^{\mathrm{c}}$ \\
\hline Poleto et al., 2009 & Brazil & 0.8 & Geochem, C & $<63$ & SSA & -- & -- \\
\hline Pulley et al., 2015a & United Kingdom & 1634 & Geochem, Mags, RN & $<63$ & SSA / None & -- & -- \\
\hline Russell et al., 2001 & United Kingdom & $1.5,4$ & $\begin{array}{c}\text { Geochem, Mags, RN, C, } \\
\text { N }\end{array}$ & $<2,10,38,63$ & $\begin{array}{l}\text { Tracer specific particle } \\
\text { size correction factor }\end{array}$ & -- & -- \\
\hline Tiecher et al., 2016 & Brazil & 1.2 & Geochem, DRIFTS, XRD & $<63$ & -- & -- & -- \\
\hline Sherriff et al., 2015 & United Kingdom & 11 & Geochem, Mags & $<125$ & -- & -- & -- \\
\hline Smith and Blake 2014 & United Kingdom & 920 & Geochem, RN, C & $<63$ & SSA / None & -- & -- \\
\hline Stone et al., 2014 & Canada & 751 & Geochem, C & $<63$ & SSA & -- & -- \\
\hline Walling et al., 1993 & United Kingdom & 12,46 & RN, Mags, C,N & $<63$ & $\begin{array}{l}\text { None (Mags) and } \\
\text { source correction } \\
\text { (FRN) }\end{array}$ & -- & -- \\
\hline Walling et al., 1999 & United Kingdom & 818,3315 & Geochem, Mags, RN,C,N & $<63$ & SSA & -- & -- \\
\hline Zhang and Liu, 2016 & United States & 15.6 & Geochem, C,N & $<53$ & -- & -- & -- \\
\hline
\end{tabular}

a SSA correction was only used for the composite fingerprinting approach, not the CSSI tracers

${ }^{b}$ Only geochemistry data is available

c Sediments not sources

${ }^{\mathrm{d}}$ Dispersed with Calgon and then sonified

e Fractional mass of each sediment size fraction was multiplied by their corresponding source tracer property and summed

${ }^{f}$ Dispersed with sonification 


\section{Main Approaches to Address Particle Size}

299

Owing to the potential of particle size to affect the values of tracer properties, researchers have adopted two main approaches to predict or mitigate particle size effects on sediment source fingerprints: fractionation and particle size corrections. Tables 1 to 5 summarize the different approaches used by researchers to address particle size for fallout radionuclides (Table 1), carbon and nitrogen parameters (Table 2), elemental geochemistry (Table 3), mineral magnetic properties (Table 4) and combinations of multiple parameters in a composite fingerprinting approach (Table 5).

\subsection{Fractionation}

To address particle size impacts on sediment fingerprint properties, researchers often fractionate both their sediment and source samples to a specific and comparable particle size fraction using settling based on Stokes' Law or sieving. The objective is to minimize potential sorting-induced differences between source and sediment properties. Conceptually, any particle size fraction can be isolated to attempt to achieve this objective, though it is mainly the $<10 \mu \mathrm{m}$ and $<63 \mu \mathrm{m}$ fractions that have been isolated in sediment source fingerprinting research.

The $<10 \mu \mathrm{m}$ fraction is predominantly used in Australia to research the source of very fine silt and clay material. The logic supporting the use of the $<10 \mu \mathrm{m}$ fraction is that it is the dominant size fraction being transported in these river systems and this fraction has the greatest ecological and water quality impact (Douglas et al., 2003; Olley and Caitcheon, 2000). The $<10 \mu \mathrm{m}$ fraction is isolated in settling columns based on Stokes' Law with assumptions of constant temperature, roundness and density of the particles (Fontaine et al., 2000; Walden and Slattery, 1993).

The $<63 \mu \mathrm{m}$ fraction is arguably the most adopted sediment tracing particle size fraction (Devereux et al., 2010; Pulley et al., 2015a; Walling et al., 1993). This fraction represents the silt and clay material that is transported preferentially as suspended sediment in riverine, lacustrine, estuarine and coastal systems. The $<63 \mu \mathrm{m}$ fraction is also one of the smallest dry/wet sieve sizes at the fine sand to silt size boundary (i.e. an operationally defined fraction/separation). Research examining the different impacts of wet sieving and dry sieving on biogeochemical properties may be warranted in the sediment source fingerprinting context, along with research on the impact of different pre-treatments to disperse aggregates prior to analyses (Tables 1-5). 
326

327

328

329

330

331

332

333

334

335

336

337

338

339

340

341

342

343

344

345

346

347

348

One often overlooked component of addressing particle size is that the fraction isolated should include the range of fingerprint property values in the potential sources. This is particularly important for elemental geochemistry. For example in Figure 4, it is apparent that isolating the $<2 \mu \mathrm{m},<10 \mu \mathrm{m}$ and $<63$ $\mu \mathrm{m}$ fractions will likely result in different elemental compositions for the three sources based on the particle size fraction selected. This may be particularly important with mineral magnetic tracer properties where different signatures exist in the $<32$ and the $32-63 \mu \mathrm{m}$ soil and sediment fractions, indicating that sieving to $<63 \mu \mathrm{m}$ may be inappropriate in some regions (Pulley et al., 2015b).

A second overlooked component is that the particle size fraction isolated for sediment property analyses should directly relate to the research objective. For example, researchers have shown that if the objective is to examine the source of material degrading the Great Barrier Reef near Australia, the $<16 \mu \mathrm{m}$ particle size fraction should likely be targeted (Bartley et al., 2014). Researchers should support their choice of particle size fraction by relating it to the particle size being transported in the stream system (Wallbrink et al., 1999), or the particle size of the sediment-associated contaminants of interest (Olley and Caitcheon, 2000). For both approaches, there is a trade-off between fractionating down to the finest particle size (e.g. $<2 \mu \mathrm{m}$ ) versus using a broader particle size fraction (e.g. $<63 \mu \mathrm{m}$ ) that may require more steps to address discrepancies between source and sediment particle size distributions. In some regions, the abundance of material present in the sediment and sources may even control the particle size selected as there may not be sufficient $<10 \mu \mathrm{m}$ or even $<63 \mu \mathrm{m}$ material available for analysis. Indeed, the results from sediment source fingerprinting research will only relate to the particle size fraction examined. If narrow particle size ranges are fractionated (e.g. $<2 \mu \mathrm{m}$ or $<10 \mu \mathrm{m}$ ), the results from the source apportionment modelling will only apply to that fraction and not the entire suspended sediment load more generally (Mukundan et al., 2012).

Ultimately, the key to using fractionation to address particle size differences is to ensure that the grain size distribution of the source material is similar to that of the sediment sampled (i.e. Poulenard et al., 2009). For example, Sherriff et al. (2015) found that the $90^{\text {th }}$ percentile of the suspended sediment distribution for select samples was frequently $>63 \mu \mathrm{m}$ and thus these authors sieved samples to $<125 \mu \mathrm{m}$. Furthermore, it is important to understand the relationship between particles size distribution and event magnitude, and even how this relationship is impacted by seasonality (Bogen, 1992; Lewis, 1996). In this regard, it would be beneficial for fingerprinting studies to report summary statistics for particle size data of both source soils and sediments to present this important comparison. The challenge is that particle size fractionation of samples alone will not necessarily reduce the discrepancy between the fractionated 
samples (Cooper et al., 2015a; Kersten and Smedes, 2002). If there are significant differences between source and sediment particle size distributions remaining after fractionation, particle size corrections are potentially required.

\subsection{Particle Size Corrections}

To mitigate differences in the particle size distributions of source soil and sediment, corrections have been applied based on particle size characteristics of source and sediment material (Collins et al., 1996; Slattery et al., 1995; Walling and Woodward, 1992; Walling et al., 1993) (Tables 1, 4, 5). The initial corrections reconstructed particle size distribution and tracer parameters of the source materials to allow for the direct comparison with the sampled sediment (Slattery et al., 1995; Walling and Woodward, 1992; Walling et al., 1993). The objective of these corrections was to reduce the impact of source and sediment particle size distributions on tracer parameters prior to quantifying source contributions.

A second approach to particle size corrections is the incorporation of a within-model weighting (Collins et al., 1996) which has been broadly applied (Collins et al., 2012; Poleto et al., 2009; Stone et al., 2014; Walling et al., 1999). The within-model correction incorporates some variant of a particle size weighting, such as the ratio of the mean SSA in sediment to the mean SSA in each source (Collins et al., 1996; Collins et al., 2010). The logic supporting the use of a SSA derived correction is that particle size and specific surface area are closely related (Horowitz, 1991). Surface area is one of the most important controls on sediment trace element concentrations as the majority of these interactions are postulated to be related to surface area chemistry or surface area reactions (Horowitz and Elrick, 1987).

Although widely applied, there are acknowledged limitations and challenges with particle size corrections. Russell et al. (2001) reported a large range in SSA between different sources and sediment for a catchment in the UK and found that a linear-based particle size correction may be inappropriate in some cases. Smith and Blake (2014) further demonstrated that the fundamental assumption of some particle size corrections (i.e. positive linearity between particle size and tracer concentration) does not apply to all tracer properties or equally to properties from different sources (Figure 5). These authors reported that this basic assumption of linearity needs to be constantly examined and its dependence on analytical methods (e.g. acid leached versus total digestion for ICP-MS analyses) should also be considered. Particle size corrections, if adopted, probably should be more rigorous than simple SSA ratio model weightings (e.g. Motha et al., 2002; Motha et al., 2003; Russell et al., 2001; Slattery et al., 1995; Walling and Woodward, 

effects simultaneously with a stepwise multiple regression analysis model (Kraushaar et al., 2015).

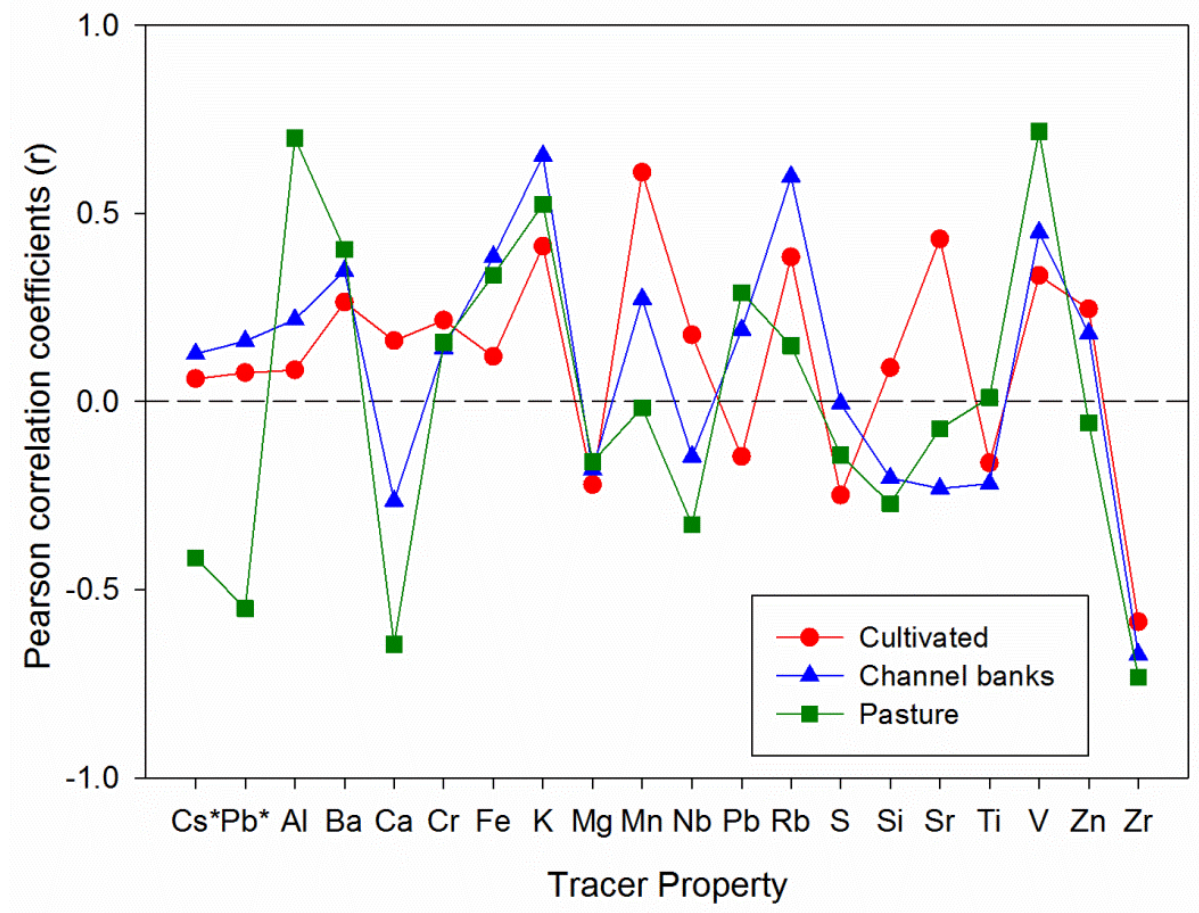

Figure 5: Pearson correlation coefficients $(r)$ between Specific Surface Area (SSA) and tracer property for three sources from Smith and Blake (2014) (data from Table 1) with the * indicating fallout radionuclides $\left({ }^{137} \mathrm{Cs}\right.$ and $\left.{ }^{210} \mathrm{~Pb}_{\mathrm{ex}}\right)$ on the $\mathrm{x}$ axis and the remainder being elements.

The challenge is that there are a variety of non-linear responses between sediment biogeochemistry and particle size (Motha et al., 2002; Russell et al., 2001; Smith and Blake, 2014). There are assumptions with particle size measurements that are often not acknowledged (e.g. all particles are spherical and transported as discrete particles) and there are uncertainties and errors with laser particle size measurements that are not often reported nor propagated into total modelling uncertainty. The impact of these errors varies for different particle size distributions, with a notable increase in instrumentation error with decreasing particle size (Merkus, 2009) (Figure 6). One question for future research is whether or not potential errors on the SSA analysis could result in a substantially different interpretation of the results. Further, stable soil aggregates and agglomerated composite particles that are formed by particle to particle interaction after mobilization (Droppo et al., 2005) may also impact relationships between source and sediment fingerprints. Given the potential uncertainty of accurate SSA ratio-based corrections, 

transport processes and/or sample fractionation (e.g. Koiter et al., 2013a; Martinez-Carreras et al., 2010).

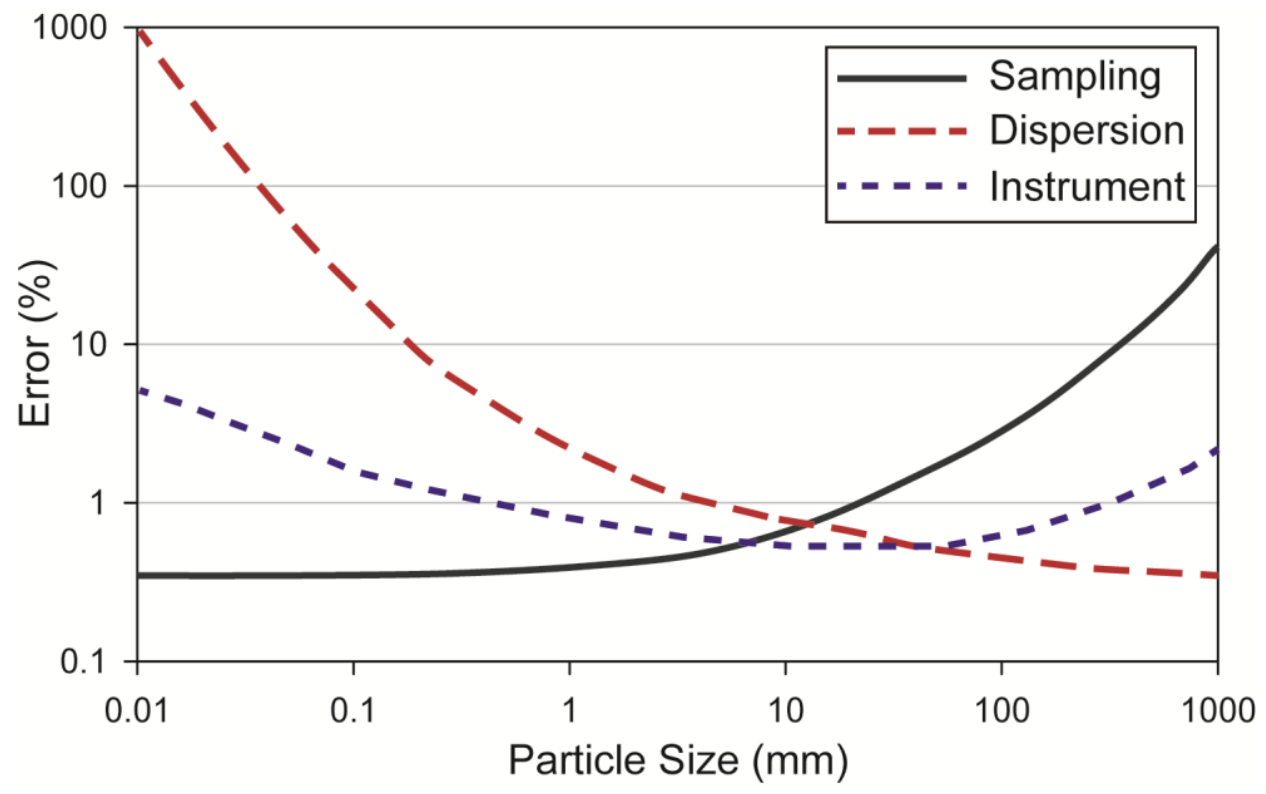

Figure 6: Relationship between potential sources of error and particle size distribution, adapted from Merkus (2009).

\subsection{Combining Size Fractionation and Corrections Procedures}

Moving forward, the first step towards addressing particle size should be to fractionate the source and sediment material according to the research question (Table 6), which in turn requires information on the particle size composition of the sediment and/or contaminants in question. Second, the results of this fractionation should be assessed to determine whether the particle size distributions of the source and sediment material are not significantly different. If they are significantly different, third, the application of corrections to tracer properties is probably required for each source with enough samples to ensure source representativeness. Particle size corrections are likely to be more effective if researchers are working with a wide target fraction that is susceptible to sorting effects. The actual impact of the corrections should also

412 be assessed and reported upon, particularly the impact of the corrections on the original basis for source 413 discrimination. The optimal approach for understanding the impact of particle size corrections involves 414 the comparison of biogeochemical properties from samples fractionated across a variety of particle size 415 fractions (e.g. He and Walling, 1996; Laceby et al., 2015b; Russell et al., 2001). Understanding the impacts 416 of particle size on tracer properties should be one of the fundamental first steps when trialling new tracer properties in sediment source fingerprinting research. 


\section{Alternative Techniques to Address Particle Size}

419 Although particle size fractionation and particle size corrections are the two main approaches used to 420 account for any predictable changes in biogeochemical properties during sediment generation, 421 transportation and deposition processes, the challenges with particle size selectivity have opened up new 422 avenues to explore alternative approaches and research directions.

\section{$423 \quad 4.1$ Tributary (or Confluence) Tracing}

424 One approach to mitigating potential particle size impacts on sediment source fingerprinting is to 425 incorporate a tributary tracing or confluence tracing research design (Caitcheon, 1993; Hatfield and 426 Maher, 2008; Laceby et al., 2015a; Olley and Caitcheon, 2000; Vale et al., 2016; Walling et al., 1999). The 427 concept of a tributary tracing approach is that researchers sample sediment in the different upstream 428 tributaries and use these samples as a potential source of sediment sampled further downstream (Figure 429 7). The tributary sampling approach models sediment as a source and a sink, thus removing a significant 430 proportion of the impact of potential particle size enrichment on fingerprint properties. This approach has 431 also been recently applied to a lacustrine environment by Le Gall et al. (2016) who modelled the source of 432 material sampled in the downstream section of a pond in France based on the geochemical properties of 433 deposited sediment in the inlets of the two main tributaries.

434 There may be potential particle size enrichment or depletion impacts on fingerprint properties that may 435 occur during transportation and settling processes, although the most significant particle size enrichment 436 typically occurs during the initial stages of mobilization and transportation that often occurs on hillslopes 437 and in ephemeral systems (Stone and Walling, 1997). As material moves into the riverine system, sediment 438 particle size often becomes increasingly uniform and thus fewer differences may be anticipated. Of course, 439 there are always exceptions. For example, Koiter et al. (2015) used a recirculating flume to demonstrate 440 that it was not only distance travelled that impacted particle size, but also channel bed characteristics such 441 as roughness, porosity and inter-gravel flow. Therefore, the tributary tracing technique may have a limited 442 ability to mitigate particle size impacts where tributaries have distinctly different channel bed 443 characteristics and/or where there is a considerable distance between tributary and downstream sampling 444 sites.

Table 6: Overview of particle size implications at different steps in the sediment source fingerprinting research process

Step Particle Size Implications


- Fractionate source and sediment material according to the research question

1. Research

Objective

2. Research Design

- The particle size fraction analyzed should relate to the dominant particle size being transported in the system or the dominant particle size of the sediment-associated contaminant of interest

- Consider the potential impacts of particle size on the research design and the different opportunities available to address and investigate particle size impacts on sediment source fingerprinting results

- Consider using a tributary tracing sampling design or edge-of-field samplers to mitigate particle size impacts on tracing parameters

- Plan and budget particle size analyses for sediment and source materials to understand whether or not there are significant impacts of particle size selectivity on the tracer parameters in the study region

A) Fractionation

- Ensure the particle size distribution of the source material is not significantly different than that of the sediment

- Consider the potential impact of fractionation (e.g. sieving/settling) on biogeochemical properties and potential challenges with stable soil aggregates and sediment flocculants

3. Sample

Processing, Analysis, Modelling
B) Corrections

- Consider corrections if fractionation does not remove the differences between source and sediment particle size distributions

- Always plot and assess the impact of the corrections on tracer parameters and source discrimination

C) Modelling

- Consider modelling different particle size fractions or comparing results with and without corrections on artificial mixtures to truly understand particle size impacts in the study region

- Present the relationship between particle size and the tracer properties of interest

- Assess and report on the impact of fractionation and corrections in the results with

5. Results an emphasis on any potential impacts on the original basis of source discrimination

- Present summary statistics for particle size distributions to facilitate comparisons between particle size distributions in source and sediment material

6. Discussion

7. Supplementary Information
- Discuss the impact of particle size in relation to other sediment source fingerprinting studies

- Provide corrected and uncorrected data for parameters used and all particle size data for future use by the research community (including sample coordinates, $\mathrm{d}_{50}$, $d_{90}$, SSA and pre-treatments used prior to particle size analyses). 


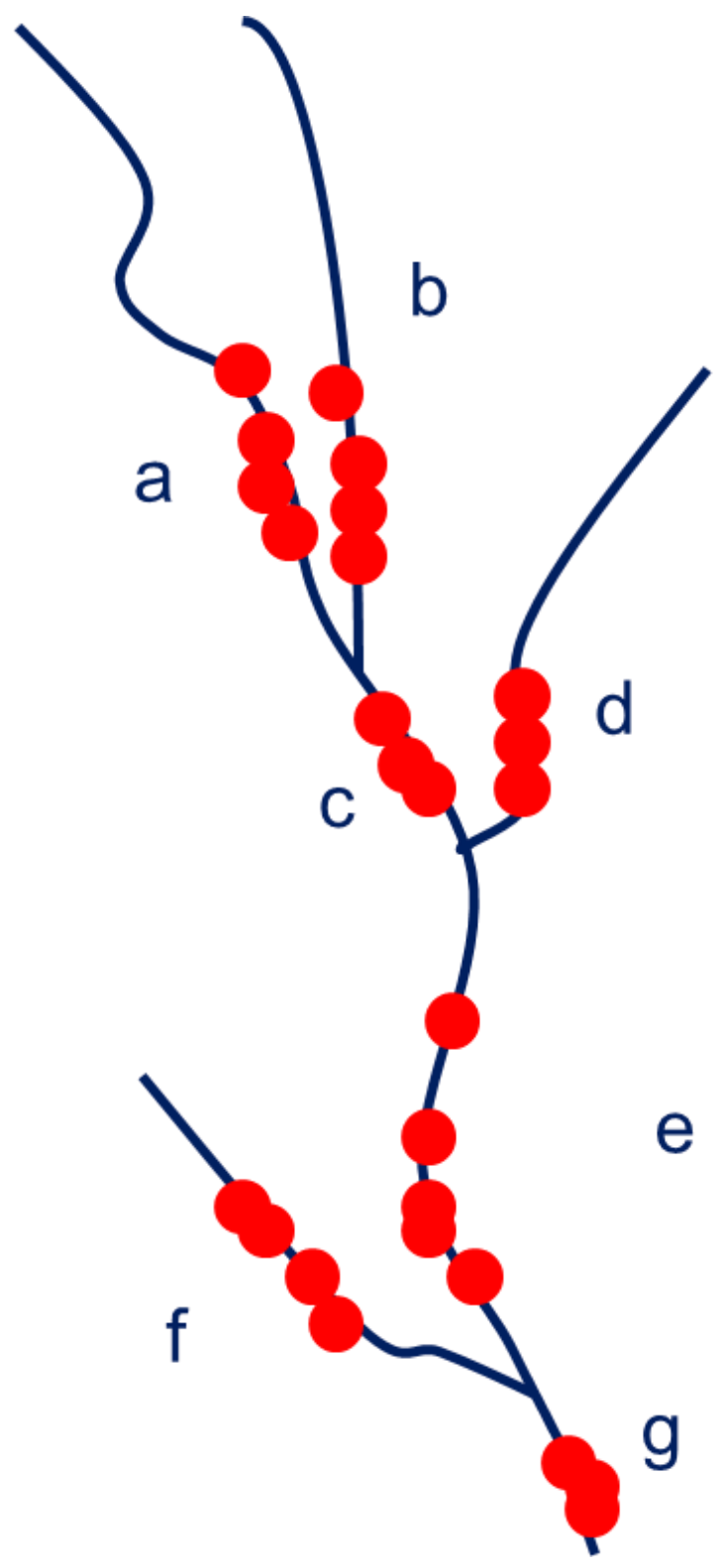

Figure 7: An example of a sampling design with the tributary tracing technique where the letters indicate the different tributaries that could be sampled in this theoretical catchment. In this situation, sediment collected at sites $\mathrm{c}$, e and $\mathrm{g}$ is compared to sediment collected where it may be able to infer which tributaries (i.e. a, b, d or f) were the main sediment sources. 
The tributary tracing technique may also address potential challenges that arise from variations in tracer

448 properties at the sub-catchment or reach scale. For example, it is conceivable that magnetic properties or

449 elemental concentrations may vary significantly at the subcatchment scale. The tributary tracing approach 450 may capitalize on these variations, incorporating them into contrasts between different sources, in this 451 instance, between different tributaries. A question for future research is what should be the benchmark 452 for indicating that the spatial variability in tracer properties has been sufficiently constrained, let alone the 453 heterogeneity in potential fractionation of different particle sizes?

454 Future research needs to examine the potential of tributary tracing research designs to address particle 455 size enrichment impacts on biogeochemical tracer properties, particularly when comparing sediment sampled instream to material deposited in lakes and reservoirs, and tributaries with different channel bed roughness. Indeed, more research is also required to examine the impact of in-stream sampling approach (e.g. lag deposits, time-integrated samplers, instantaneous samplers, and channel bed-material samplers) on sediment characteristics as different in-stream sampling methods may result in particle size biases that may impact source modelling results. A sampling design with sufficient replication of these different instream sampling methods in various catchments around the world may indeed provide further understanding regarding the relationship between particle size and sampling methodology and how the sediment sampling design may impact fingerprint properties and even potentially mixing model results.

\subsection{Edge-of-Field Samplers}

An alternative technique that may limit potential particle size effects on biogeochemical tracers during mobilization and initial transportation phases is the installation of edge-of-field samplers (Panuska et al., 2008; Wallbrink and Murray, 1993). Edge-of-field sampling approaches capture sediment after the initial mobilization and transport processes and are an alternative technique for examining whether particle size corrections are required (Evrard et al., 2016), or if they have been applied correctly (Foucher et al., 2015).

470 Conceptually, samplers installed on USLE plots (Brooks et al., 2014; Wischmeier and Smith, 1978) could 471 opportunistically sample material mobilized from hillslopes. Gerlach troughs (Gerlach, 1967) could sample 472 suspended sediment on hillslopes for further analyses after it has been mobilized and transported 473 downslope. Similarly, V-notch weirs combined with automated sediment samplers may also provide an 474 effective approach for sampling hillslope sediments in ephemeral gullies and other ditch type landscape 475 features (Freebairn and Wockner, 1986). 
476 The key is to understand the impact of the initial mobilization and transport processes on both particle 477 size and the fingerprinting parameters of interest. For example, Evrard et al. (2016) demonstrated that 478 there was no significant difference between the fallout radionuclide activity concentrations in surface 479 soils, riverine sediments and sediments sampled with edge-of-field samplers in Laos. Conversely, in a 480 lowland and well-drained agricultural catchment in France, Foucher et al. (2015) sampled material in an 481 ephemeral rill during a rainfall event to confirm both the hyper enrichment of fine particles in overland 482 flow $(<2 \mu \mathrm{m})$ and also to provide confidence that both the SSA- and Th-based corrections were applied 483 effectively. Further research is required to examine the potential of edge-of-field samplers to improve our 484 understanding of particle size impacts on biogeochemical tracer properties and understand how to apply 485 these samplers for a range of complex source types (e.g. unpaved roads and farm tracks). For example, it 486 would be beneficial to compare the impact of tributary sampling technique, an edge-of-field sampling 487 approach and top soil grab sampling on particle size distributions and to investigate whether or not these sampling approaches mitigate particle size effects on biogeochemical tracers.

\subsection{Multiple Fraction Tracing}

490 Another technique to examine differences and potential particle size effects on conservative behavior is 491 tracing different particle size fractions (Caitcheon, 1998; Haddadchi et al., 2015; Laceby et al., 2016). 492 Although there has been a significant amount of research invested into developing particle size corrections 493 (Collins et al., 1996; Russell et al., 2001; Walling et al., 1993), less frequently have the different fractions 494 been traced and the results from tracing different size fractions been examined.

Caitcheon (1998) reported that source contributions from a sedimentary rock tributary basin varied only 496 by $13 \%$ (i.e. from $63 \%$ to $76 \%$ ) when fingerprinting with mineral magnetic properties from different particle 497 size fractions ( $<63 \mu \mathrm{m}, 63-125 \mu \mathrm{m}, 125-250 \mu \mathrm{m}$ and $250-500 \mu \mathrm{m})$. This author reported that the 63-125 $498 \mu \mathrm{m}$ fraction was most likely representative of the bulk material being transported in this particular 499 catchment. Using elemental geochemistry, Haddadchi et al. (2015) traced the fractionated <10 $\mu \mathrm{m}, 10-63$ $500 \mu \mathrm{m}$ and 63-212 $\mu \mathrm{m}$ fractions. These authors found that although the maximum difference was high (33\%), 501 there was $<15 \%$ mean absolute difference between modelled source contributions with these fractions 502 (Figure 8). In summary, Haddadchi et al. (2015) indicated that their results highlight the importance of 503 fractionating the particle size most relevant to the management objective of the research. 


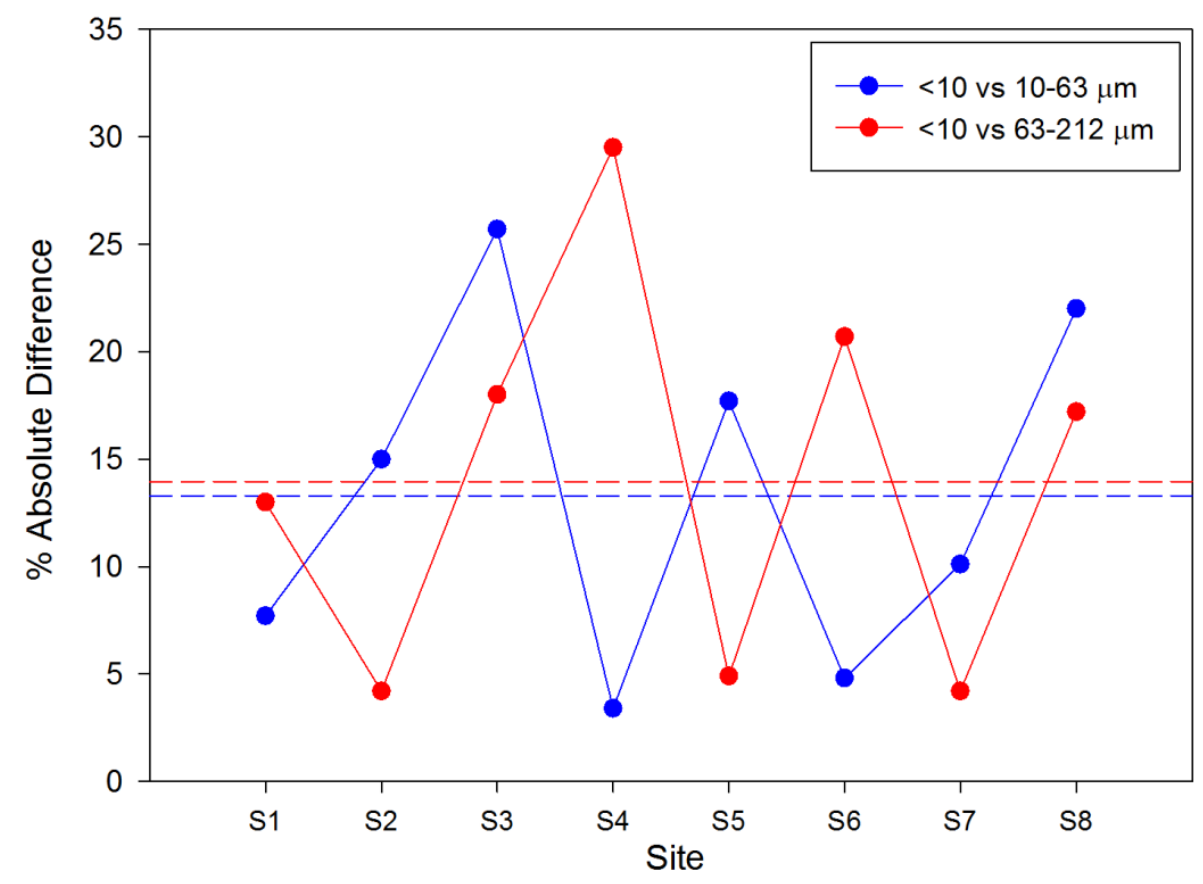

Figure 8: Mean absolute differences (dashed lines) in the source contributions between the $<10 \mu \mathrm{m}$ and the $10-63 \mu \mathrm{m}$ (blue) and between the $<10 \mu \mathrm{m}$ and the $63-212 \mu \mathrm{m}$ fractions (red) for eight sites in Australia plotted with data from Figure 9 in Haddadchi et al. (2015).

505 Laceby et al. (2016) also compared the impact of tracing different particle size fractions for three

506 catchments in the Fukushima region in Japan. These authors compared the relative model difference from tracing the $<63 \mu \mathrm{m}$ and the $<2 \mathrm{~mm}$ fractions with TOC, TN, $\delta^{13} \mathrm{C}$, and $\delta^{15} \mathrm{~N}$ for 76 sediment samples taken

508 in three different catchments (Figure 3). The authors reported a maximum modelled average difference 509 between the $<2 \mathrm{~mm}$ and $<63 \mu \mathrm{m}$ fraction of $14 \%, 11 \%$ and $7 \%$ for the three catchments, and a mean 510 relative difference of only $6 \%$ (SD 3\%) for all possible modelled source contributions. The limited 511 differences between these models was likely driven by the fact that only $19 \%$ (SD 13\%) of the material in 512 these sediment samples was $<63 \mu \mathrm{m}$ compared to $23 \%$ (SD 12\%) of the material for the source samples, 513 indicating that $\sim 80 \%$ of material was $>63 \mu \mathrm{m}$ for both source and sediment samples. A similar approach 514 should be applied in catchments with finer sediment transiting the system to characterize the potential 515 impact of fine sediment material on modelling results when tracing different fractions.

516 These studies raise interesting questions regarding what are the actual differences in mixing model results 517 arising from the impacts of particle size on tracer properties. Are these impacts greater than analytical and 518 model uncertainty? Is this particle size impact significant for management objectives? These fundamental 
research questions present an opportunity for sediment source fingerprinting research with a focus on

520 methodological sensitivity to particle size effects in different systems. The challenge moving forward will

521 be for researchers to quantify the solid discharge in each particle size fraction in order to compare and 522 model both the relative source contributions (i.e. unweighted) and the absolute source contributions (i.e. 523 weighted by the abundance in each fraction), which could be significantly different.

\section{Particle Size Opportunities}

525 After material is mobilized from sources, sediment fingerprinting researchers often conceptualize riverine 526 systems as a black box, where the processes that occur between source and sediment sampling are not 527 well understood (i.e. Figure 3 in Koiter et al., 2013b). If researchers focus on furthering our understanding 528 of the relationship between particle size and biogeochemical properties, they may simultaneously start to examine processes occurring within this black box. De-convoluting the complex relationship between

530 particle size and biogeochemical properties may provide significant insight into the processes of sediment 531 mobilization, transport and deposition within this black box, including the potential unique behaviour of 532 different sediment source parameters. Accordingly, there are multiple opportunities to advance sediment 533 source fingerprinting research and further our understanding of the complex relationship between particle 534 size and tracer parameter predictability.

\section{$535 \quad 5.1$ Mineralogy, Particle Size and Elemental Geochemistry}

536 The most important research objective and opportunity regarding particle size is to increase our 537 understanding of sediment tracer predictability. One approach to improving this predictability is 538 connecting particle size, mineralogy and elemental geochemistry. For example, in Figure 4, there is a clear 539 connection between sediment mineralogy and particle size, which will have direct ramifications for the 540 elemental compositions of sediment sources. Significant advances in sediment source fingerprinting 541 research are likely to be made through connecting these three components. More research into sediment 542 mineralogy may result in novel tracing techniques that are grounded in a logical basis for source 543 discrimination (e.g. Afshar et al., 2016; Bainbridge et al., 2016; Gingele and De Deckker, 2004; Tiecher et 544 al., 2016), that also provide significant information on the complex relationship between particle size and 545 elemental concentrations.

546 Mineralogy was one of the first sediment fingerprinting properties (Klages and Hsieh, 1975; Wall and 547 Wilding, 1975) and returning to incorporate mineralogy more directly into sediment tracing may provide 548 significant insights into particle size impacts on elemental compositions. This may be achieved, although 
549 indirectly, through using Diffuse Reflectance Infrared Fourier Transform Spectrometry (DRIFTS) to identify 550 mineralogical groups (e.g. calcite, aluminosilicates, quartz) and discriminate between sediment lithological 551 sources (Poulenard et al., 2012). The use of DRIFTS and other spectroscopy approaches to tracing sediment 552 sources has the potential to develop a strong link to mineralogy and potentially estimate other 553 conventional tracer parameters like texture (Balsam and Deaton, 1996; Ortiz et al., 2009). Other 554 approaches such as clay mineral ratios (e.g. illite/illite + expandable clays) have also shown promise to 555 trace sediment provenance (Bainbridge et al., 2016; Douglas et al., 2006a; Douglas et al., 2006b). 556 Connecting clay mineralogy to element geochemistry and particle size will likely provide complementary 557 information relating to each of these fundamental sediment property characteristics.

\section{$558 \quad 5.2$ Elemental Ratios and Elemental Normalisation}

559 Moving a step beyond incorporating mineralogy more effectively into sediment tracing research is the 560 potential for incorporating approaches from other disciplines to address particle size effects. For example, 561 in the sediment provenance literature, elemental ratios have long been used to investigate changes in 562 particle size. In particular, the $\mathrm{Al} / \mathrm{Si}$ ratio is used as a proxy for particle size in sediment provenance 563 research (Figure 9) (Bouchez et al., 2011). Other ratios may indeed be effective, such as the Ca/Al ratio 564 (Chen et al., 2014), along with particle size sensitive elements such as Ti (Bábek et al., 2015), or even simply clay content (Szava-Kovats, 2008). For example, studies reconstructing the evolution of metal enrichment ratios in sediment have also normalized elemental concentrations to $\mathrm{Sc}, \mathrm{Al}, \mathrm{Si}$, Li or Th to minimize particle size impacts when examining contamination trends (Ayrault et al., 2010; Clark et al., 2014; Grosbois et al., 2012; Kersten and Smedes, 2002; Le Cloarec et al., 2011). Indeed, there are multiple approaches from the sediment provenance field (Armstrong-Altrin et al., 2015; Bábek et al., 2015; Owens et al., 2016; Singh et al., 2005) that present significant opportunities for enhancing the sediment source fingerprinting technique (e.g. Vale et al., 2016).

572 Different elemental and lithogenic radionuclide ratios have been used previously to address particle size 573 and density related enrichment in sediment source fingerprinting research. For example, Olley and Murray 574 (1994) demonstrated that although the concentrations of thorium (Th) isotopes varied with particle size, 575 the ${ }^{230} \mathrm{Th} /{ }^{232} \mathrm{Th}$ ratio remains constant, with sorting by density or particle size producing the same ratio as 576 the bulk soil. Caitcheon (1998) and Murray et al. (1993a) incorporated ratios directly into the mixing model 577 process for mineral magnetics and radionuclides, respectively. Although these modelling approaches used 578 the actual ratio lines to quantify source contributions, they demonstrate the utility of incorporating ratios 579 directly into the mixing model process to address particle size enrichment. More research is required to 
examine whether similar approaches may also provide a technique for normalizing particle size effects with frequentist or Bayesian mixing models, or even more insight into the foundation for elemental

582 discrimination between sediment sources. For example, the interrelationships between particle size and 583 biogeochemical tracer properties indicate that particle size may directly contribute to the formation of 584 some contrasts in sediment fingerprints between sources. Accordingly, further advances in understanding 585 these relationships, with experimental designs incorporating different particle size fractions, may provide 586 additional understanding for the basis of discrimination between sediment sources.

\section{$587 \quad 5.3$ Particle Dynamics}

588 The nature of cohesive sediment transport, and particularly fine sediment transport, is fundamentally 589 complex where the majority of particles are transported as flocs, or composite particles, that are 590 comprised of organic matter, smaller particles and mineral components with a complex structure (Droppo 591 et al., 2005; Walling and Collins, 2016). The presence of these soil aggregates and sediment flocs will have 592 a significant impact on particle size selectivity during sediment mobilization, transportation and deposition 593 processes (Beuselinck et al., 2000). The behaviour of material during these processes is a function of 594 density, aggregate stability, grain shape and grain size (D’Haen et al., 2012).

595 The impact of grain abrasion and disaggregation on ${ }^{137} \mathrm{Cs}$ concentrations was examined by Dyer and Olley 596 (1999) who reported that the fraction produced by abrasion had essentially similar ${ }^{137} \mathrm{Cs}$ concentrations as 597 the corresponding fraction $(<40 \mu \mathrm{m})$ in non-disturbed soil. Conversely, Crockford and Olley (1998) found 598 that breakage and abrasion processes had a substantial impact on mineral magnetic properties, reducing 599 concentrations in a granitic soil and increasing concentrations in a sedimentary soil. These authors 600 concluded that a tributary or confluence tracing approach should mitigate the impact of these processes 601 on mineral magnetic properties. Although these studies examined the disaggregation of sediments, 602 Droppo et al. (2005) suggested that the actual nature of aggregates and flocs is rarely considered in studies 603 of sediment transport and sources. 


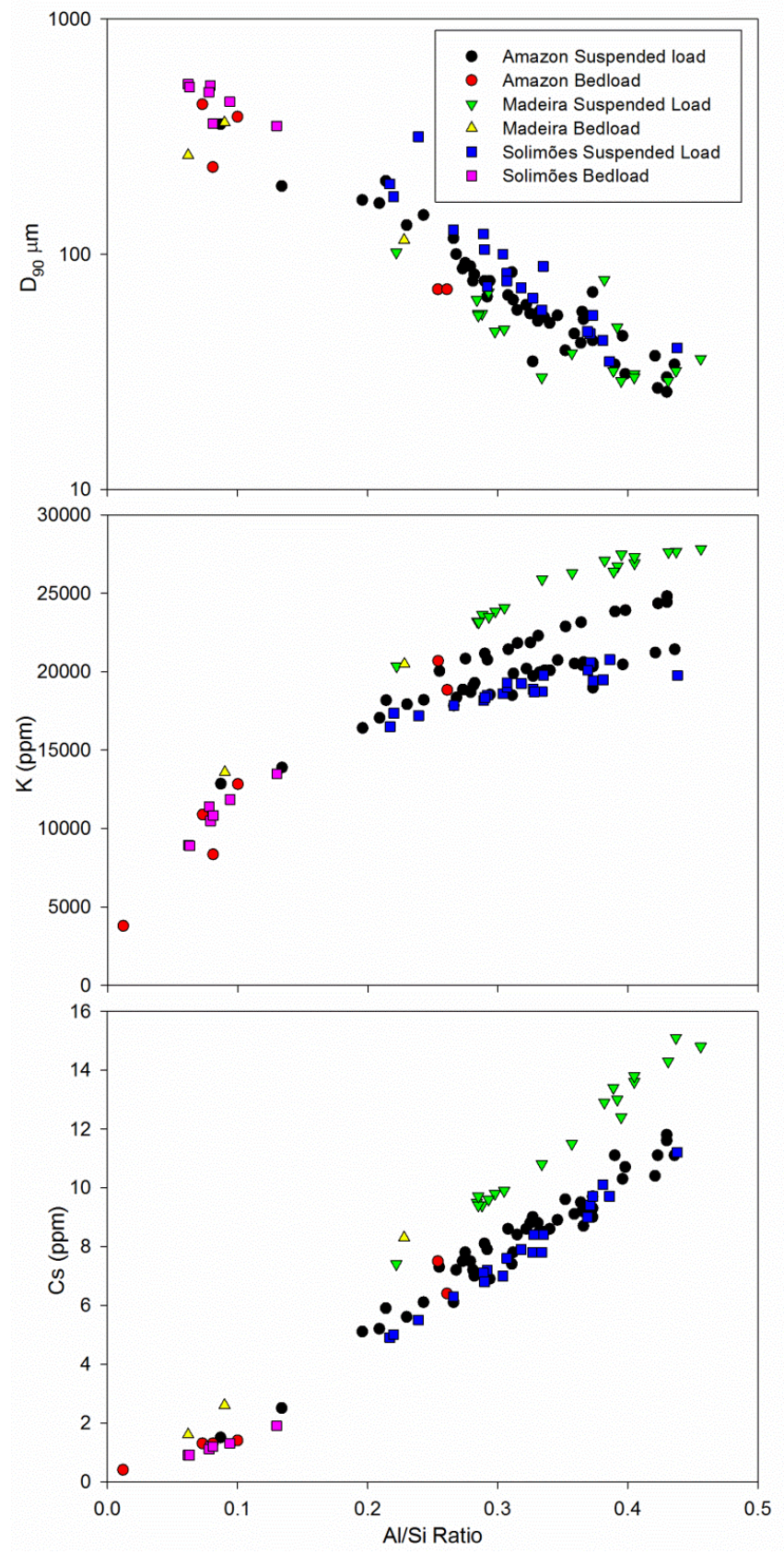

Figure 9: Scatter plots of the relationship between the $\mathrm{Al} / \mathrm{Si}$ ratio and $\mathrm{D}_{90}, \mathrm{~K}$, and $\mathrm{Cs}$ (ppm) from samples from different tributaries of the Amazon catchment with data from Tables 1 and 2 from Bouchez et al., 607 (2011).

608

609 Accordingly, there is an opportunity to improve our understanding of sediment transport processes by 610 further incorporating the nature of the material being transported more directly into the methodology of 611 sediment fingerprinting projects. This is important as the sediment fractions isolated by density may be 
612 different than those identified by particle size analysis (Gregorich et al., 2006). Different fractionation 613 methods (e.g. wet sieving, dry sieving, grinding) may fragment aggregates which could result in different 614 biogeochemical properties in analyzed aliquots. This may be particularly true with respect to different 615 techniques and conditions for wet and dry sieving, and the use of Stokes' law and settling columns to 616 isolate different particle size fractions. Different source and sediment material (e.g. platy, spherical, and 617 rod-shaped grains) may respond differently to fractionation methods (Droppo et al., 2005; Hatfield, 2014). 618 Different pre-analysis treatments (e.g. sonification, chemical dispersion, physical dispersion) may also impact the biogeochemical fingerprints of interest. Laboratory determined grain size distributions will most likely differ significantly from those in the field owing to the physical and often chemical 621 disaggregation of flocs and aggregates during the laboratory fractionation process (Phillips and Walling, 622 1995; Walling and Collins, 2016).

623 One major research opportunity is whether these alterations between laboratory and field, and the impact 624 of aggregates, are significant to sediment fingerprinting modelling results, or fall within the range of 625 analytical and modelling uncertainty. For example, if soil aggregates and sediment flocs form and/or 626 evolve during sediment mobilization and transportation processes, this may result in a form of non627 conservative behaviour between source and downstream sink, adding uncertainty in the form of an 628 'aggregate size' effect on tracer properties. Furthermore, the impact of aggregates directly relates to the approach to sample processing, particularly whether aggregates should be chemically dispersed prior to 630 particle size fractionation or whether samples should not be disaggregated (Koiter et al., 2017). More 631 research is required to characterize the impact of aggregates, and their processing, on sediment source 632 fingerprinting research.

633 Density separation is an intriguing fractionation approach that has not received much attention in the 634 sediment source fingerprinting literature (Hardy et al., 2010). Different clay minerals have different 635 densities that may impact their separation with settling columns in the finer fractions. Furthermore, iron 636 oxides and mineral magnetic properties have been strongly related to density (Hatfield, 2014) and there 637 may be micro aggregates or sediment flocs transported in suspension with the silt or very fine sand fraction 638 because they are lighter. Importantly, these micro-aggregates and sediment flocs will have a high capacity 639 to transport contaminants; however they will have a different resistance (i.e. a lower density) relative to 640 absolute particles of a similar size, predominantly the silt fraction (Droppo et al., 1998).

641 Although density separation is time consuming and expensive, it may be more relevant to fluvial processes 642 compared to sieving the $<63 \mu \mathrm{m}$ fraction or settling the $<10 \mu \mathrm{m}$ fraction. Accordingly, it would be 
643 opportunistic to compare density and particle size separation techniques to understand their impacts on

644 sediment fingerprinting modelling results. As researchers apply tracing techniques directly to quantify the 645 relative source contributions of carbon and nitrogen (Cooper et al., 2015b; Garzon-Garcia et al., 2017), and 646 are using different carbon components to model sediment sources (Blake et al., 2012; Gibbs, 2008; 647 Hancock and Revill, 2013; Reiffarth et al., 2016) the utility of density separation may become of increasing 648 importance for tracing different carbon sources in riverine systems.

\subsection{Particle Size as a Tracer Property}

650 Situations may arise where particle size may be used as a tracer property in and of itself. The sediment 651 source fingerprinting approach is founded upon the assumptions of conservative behavior and source 652 discrimination. As noted in the introduction and throughout this review, if the sediment source properties, 653 including particle size, are predictable, they could possibly be used in sediment source fingerprinting 654 research.

655 The particle size distribution of source material is dependent on the parent material, weathering and 656 erosion processes. Accordingly, there may be situations where particle size itself may be a useful tracer 657 property, particularly where one sediment source is dominated by sandy quartz material and another by 658 fine clay material. Researchers have effectively utilized particle size to discriminate between pre- and post659 dam stratigraphy (Batuca and Jordaan Jr, 2000; Morris and Fan, 1998). Further, the particle size of reservoir 660 sediment has been traced back to the parent rock material (Abraham et al., 1999). If researchers were 661 interested in tracing material in the bed load, or material being transported off shore to oceanic 662 environments, then particle size metrics may be effective tracers in these scenarios, if they are indeed 663 predictable. There may even indeed be situations where particle shape may provide an effective 664 discriminator for determining sediment provenance (Ehrlich et al., 1980).

\section{Conclusion}

666 Sediment source fingerprinting researchers have recently tended to avoid in-depth examinations of 667 fundamental topics such as the impact of organic matter on biogeochemical properties, which tracer 668 properties are non-conservative (e.g. soluble, reactive), and what is the impact of particle size on tracer 669 property predictability. One limitation of statistically-oriented approaches to sediment source 670 fingerprinting is that they do not strive to understand the logic of tracer selection, non-conservative 671 tracers, nor particle size impacts. This is particularly limiting, as addressing conservative behaviour is 672 fundamentally more complex than simply acknowledging that sediment samples plot within their source 
673 range. Modelling, and the statistical selection of which tracer properties to model, represent only two 674 stages of the sediment source fingerprinting process; although these two steps, at times, appear to 675 dominate the recent literature. Rarely is particle size the focus of research, rather particle size is often 676 simply an acknowledged limitation that must be addressed somehow. After demonstrating that non677 conservative tracer properties affect the accuracy of sediment source fingerprinting modelling results, 678 Sherriff et al. (2015) appropriately emphasized that improved strategies to detect non-conservative tracer 679 properties should be a priority of sediment source fingerprinting research.

680 Researchers thus need to start investigating some of these fundamental assumptions and complexity at 681 the core of the sediment source fingerprinting approach. Researchers should strive to understand particle 682 size impacts and the logic of tracer selection, as they are likely to be inherently related. For example, the 683 interrelationships between particle size and biogeochemical tracer properties suggest that in many 684 instances particle size may also contribute to the formation of contrasts in sediment fingerprints between 685 sources. Approaches to address particle size will likely vary from region to region, catchment to catchment, 686 and even from event to event. Accordingly, researchers should always publish particle size and 687 biogeochemical property datasets for important regional and future comparisons, including data from 688 different particle size fractions (Kersten and Smedes, 2002). Of note, from the papers reviewed in this 689 study, only approximately $15 \%$ published the raw source and sediment data (Tables 1-5).

690 In summary, particle size dynamics presents both a challenge and an opportunity for sediment source

691 fingerprinting research. The research question, context and objective will determine the approach to 692 addressing particle size and the appropriate fraction for investigation (Table 6). Addressing particle size 693 effects is fundamental to research design, tracer selection, and sampling technique (e.g. edge-of-field 694 samplers). Advances in the understanding of particle size-biogeochemical tracer interactions will likely 695 improve the predictability and therefore accuracy of sediment source fingerprinting.

\section{Acknowledgements}

697 This research was the result of multiple discussions at European Geosciences Union annual meetings. 
Abraham, J., Allen, P., Dunbar, J. and Dworkin, S., 1999. Sediment type distribution in reservoirs: sediment source versus morphometry. Environmental Geology 38, 101-110.

Afshar, S., Saghafian, B. and Vosoughifar, H., 2016. Source apportionment of the sediments entering dam using lithological and mineralogical studies. Global Journal of Environmental Science and Management 2, 265-274.

Amundson, R., Austin, A.T., Schuur, E.A.G., Yoo, K., Matzek, V., Kendall, C., Uebersax, A., Brenner, D. and Baisden, W.T., 2003. Global patterns of the isotopic composition of soil and plant nitrogen. Global Biogeochemical Cycles 17, 1031.

Armstrong-Altrin, J.S., Machain-Castillo, M.L., Rosales-Hoz, L., Carranza-Edwards, A., Sanchez-Cabeza, J.-A. and Ruíz-Fernández, A.C., 2015. Provenance and depositional history of continental slope sediments in the Southwestern Gulf of Mexico unraveled by geochemical analysis. Continental Shelf Research 95, 15-26.

Ayrault, S., Priadi, C.R., Evrard, O., Lefèvre, I. and Bonté, P., 2010. Silver and thallium historical trends in the Seine River basin. Journal of Environmental Monitoring 12, 2177-2185.

Bábek, O., Grygar, T.M., Faměra, M., Hron, K., Nováková, T. and Sedláček, J., 2015. Geochemical background in polluted river sediments: How to separate the effects of sediment provenance and grain size with statistical rigour? CATENA 135, 240-253.

Bainbridge, Z., Lewis, S., Smithers, S., Wilkinson, S., Douglas, G., Hillier, S. and Brodie, J., 2016. Clay mineral source tracing and characterisation of Burdekin River (NE Australia) and flood plume fine sediment. Journal of Soils and Sediments 16, 687-706.

Balesdent, J., Mariotti, A. and Guillet, B., 1987. Natural ${ }^{13} \mathrm{C}$ abundance as a tracer for studies of soil organic matter dynamics. Soil Biology and Biochemistry 19, 25-30.

Balsam, W.L. and Deaton, B.C., 1996. Determining the composition of late Quaternary marine sediments from NUV, VIS, and NIR diffuse reflectance spectra. Marine Geology 134, 31-55.

Bartley, R., Bainbridge, Z.T., Lewis, S.E., Kroon, F.J., Wilkinson, S.N., Brodie, J.E. and Silburn, D.M., 2014. Relating sediment impacts on coral reefs to watershed sources, processes and management: $A$ review. Science of The Total Environment 468-469, 1138-1153.

Batuca, D.G. and Jordaan Jr, J., 2000. Silting and Desilting of Reservoirs. A.A. Balkema Publishers, Rotterdam, $357 \mathrm{pp}$.

Bellanger, B., Huon, S., Velasquez, F., Valles, V., Girardin, C. and Mariotti, A., 2004. Monitoring soil organic carbon erosion with $\delta^{13} \mathrm{C}$ and $\delta^{15} \mathrm{~N}$ on experimental field plots in the Venezuelan Andes. CATENA $58,125-150$.

Belmont, P., Gran, K.B., Schottler, S.P., Wilcock, P.R., Day, S.S., Jennings, C., Lauer, J.W., Viparelli, E., Willenbring, J.K., Engstrom, D.R. and Parker, G., 2011. Large shift in source of fine sediment in the Upper Mississippi River. Environmental Science and Technology 45, 8804-8810.

Belmont, P., Willenbring, J., Schottler, S., Marquard, J., Kumarasamy, K. and Hemmis, J., 2014. Toward generalizable sediment fingerprinting with tracers that are conservative and nonconservative over sediment routing timescales. Journal of Soils and Sediments 14, 1479-1492.

Ben Slimane, A., Raclot, D., Evrard, O., Sanaa, M., Lefèvre, I., Ahmadi, M., Tounsi, M., Rumpel, C., Mammou, A.B. and Le Bissonnais, Y., 2013. Fingerprinting sediment sources in the outlet reservoir of a hilly cultivated catchment in Tunisia. Journal of Soils and Sediments 13, 801-815.

Ben Slimane, A., Raclot, D., Evrard, O., Sanaa, M., Lefevre, I. and Le Bissonnais, Y., 2016. Relative contribution of rill/interrill and gully/channel erosion to small reservoir siltation in Mediterranean environments. Land Degradation and Development 27, 785-797.

Beuselinck, L., Govers, G., Steegen, A. and Poesen, J., 2000. Impact of soil aggregates on the size selectivity of the sediment deposition process. In: M. Stone (Editor), The Role of Erosion and Sediment 
Transport in Nutrient and Contamination Transfer, IAHS Publication No. 263, IAHS Press, Wallingford, 99-107.

Blake, W., Walsh, R., Sayer, A. and Bidin, K., 2006. Quantifying fine-sediment sources in primary and selectively logged rainforest catchments using geochemical tracers. Water, Air, \& Soil Pollution: Focus 6, 615-623.

Blake, W.H., Ficken, K.J., Taylor, P., Russell, M.A. and Walling, D.E., 2012. Tracing crop-specific sediment sources in agricultural catchments. Geomorphology 139-140, 322-329.

Blake, W.H., Wallbrink, P.J., Doerr, S.H., Shakesby, R.A. and Humphreys, G.S., 2004. Sediment redistribution following wildfire in the Sydney region, Australia: a mineral magnetic tracing approach. In: V. Golosov, V.R. Belyaev and D.E. Walling (Editors), Sediment Transfer through the Fluvial System, IAHS Publication No. 288, IAHS Press, Wallingford, 52-59.

Blake, W.H., Wallbrink, P.J., Wilkinson, S.N., Humphreys, G.S., Doerr, S.H., Shakesby, R.A. and Tomkins, K.M., 2009. Deriving hillslope sediment budgets in wildfire-affected forests using fallout radionuclide tracers. Geomorphology 104, 105-116.

Bogen, J., 1992. Monitoring grain size of suspended sediments in rivers. In: J. Bogen, D.E. Walling and T. Day (Editors), Erosion and Sediment Transport Monitoring Programmes in River Basins, IAHS Publication No. 210, IAHS Press, Wallingford, 183-190.

Bonniwell, E.C., Matisoff, G. and Whiting, P.J., 1999. Determining the times and distances of particle transit in a mountain stream using fallout radionuclides. Geomorphology 27, 75-92.

Bouchez, J., Gaillardet, J., France-Lanord, C., Maurice, L. and Dutra-Maia, P., 2011. Grain size control of river suspended sediment geochemistry: Clues from Amazon River depth profiles. Geochemistry, Geophysics, Geosystems 12, 1-24.

Bradford, J., Truman, C. and Huang, C., 1992. Comparison of three measures of resistance of soil surface seals to raindrop splash. Soil Technology 5, 47-56.

Brooks, A., Spencer, J., Borombovits, D., Pietsch, T. and Olley, J., 2014. Measured hillslope erosion rates in the wet-dry tropics of Cape York, northern Australia: Part 2, RUSLE-based modeling significantly over-predicts hillslope sediment production. CATENA 122, 1-17.

Caitcheon, G.G., 1993. Sediment Source Tracing Using Environmental Magnetism - a New Approach with Examples from Australia. Hydrological Processes 7, 349-358.

Caitcheon, G.G., 1998. The significance of various sediment magnetic mineral fractions for tracing sediment sources in Killimicat Creek. CATENA 32, 131-142.

Caitcheon, G.G., Douglas, G. and Palmer, M., 2006. Sediment Source Tracing in the Lake Burragorang Catchment. CSIRO Land and Water, Canberra, 28.

Chen, J.B., Gaillardet, J., Bouchez, J., Louvat, P. and Wang, Y.N., 2014. Anthropophile elements in river sediments: Overview from the Seine River, France. Geochemistry, Geophysics, Geosystems 15, 4526-4546.

Clark, D.E., Vogels, M.F., van der Perk, M., Owens, P.N. and Petticrew, E.L., 2014. Effects of a small-scale, abandoned gold mine on the geochemistry of fine stream-bed and floodplain sediments in the Horsefly River watershed, British Columbia, Canada. Mineralogical Magazine 78, 1491-1504.

Clark, E.H., 1985. The off-site costs of soil erosion. Journal of Soil and Water Conservation 40, 19-22.

Collins, A.L. and Walling, D.E., 2002. Selecting fingerprint properties for discriminating potential suspended sediment sources in river basins. Journal of Hydrology 261, 218-244.

Collins, A.L., Walling, D.E. and Leeks, G.J.L., 1996. Composite fingerprinting of the spatial source of fluvial suspended sediment: a case study of the Exe and Severn river basins, United Kingdom. Géomorphologie: Relief, Processus, Environnement 2, 41-53.

Collins, A.L., Walling, D.E., Webb, L. and King, P., 2010. Apportioning catchment scale sediment sources using a modified composite fingerprinting technique incorporating property weightings and prior information. Geoderma 155, 249-261. 
Collins, A.L., Zhang, Y., McChesney, D., Walling, D.E., Haley, S.M. and Smith, P., 2012. Sediment source tracing in a lowland agricultural catchment in southern England using a modified procedure combining statistical analysis and numerical modelling. Science of The Total Environment 414, 301-317.

Cooper, R.J., Krueger, T., Hiscock, K.M. and Rawlins, B.G., 2014. Sensitivity of fluvial sediment source apportionment to mixing model assumptions: A Bayesian model comparison. Water Resources Research 50, 9031-9047.

Cooper, R.J., Krueger, T., Hiscock, K.M. and Rawlins, B.G., 2015a. High-temporal resolution fluvial sediment source fingerprinting with uncertainty: a Bayesian approach. Earth Surface Processes and Landforms 40, 78-92.

Cooper, R.J., Pedentchouk, N., Hiscock, K.M., Disdle, P., Krueger, T. and Rawlins, B.G., 2015b. Apportioning sources of organic matter in streambed sediments: An integrated molecular and compoundspecific stable isotope approach. Science of The Total Environment 520, 187-197.

Crockford, R. and Olley, J., 1998. The effects of particle breakage and abrasion on the magnetic properties of two soils. Hydrological Processes 12, 1495-1505.

D'Haen, K., Verstraeten, G., Dusar, B., Degryse, P., Haex, J. and Waelkens, M., 2013. Unravelling changing sediment sources in a Mediterranean mountain catchment: a Bayesian fingerprinting approach. Hydrological Processes 27, 896-910.

D’Haen, K., Verstraeten, G. and Degryse, P., 2012. Fingerprinting historical fluvial sediment fluxes. Progress in Physical Geography 36, 154-186.

Davis, C.M. and Fox, J.F., 2009. Sediment fingerprinting: Review of the method and future improvements for allocating nonpoint source pollution. Journal of Environmental Engineering 135, 490-504.

Devereux, O.H., Prestegaard, K.L., Needelman, B.A. and Gellis, A.C., 2010. Suspended-sediment sources in an urban watershed, Northeast Branch Anacostia River, Maryland. Hydrological Processes 24, 1391-1403.

Douglas, G., Caitcheon, G. and Palmer, M., 2009. Sediment source identification and residence times in the Maroochy River estuary, southeast Queensland, Australia. Environmental Geology 57, 629639.

Douglas, G., Ford, P., Palmer, M., Noble, R. and Packett, R., 2006a. Fitzroy River Basin, Queensland, Australia. I. Identification of sediment sources in impoundments and flood events. Environmental Chemistry 3, 364-376.

Douglas, G., Ford, P., Palmer, M., Noble, R. and Packett, R., 2006b. Fitzroy River, Queensland, Australia. II. Identification of sources of estuary bottom sediments. Environmental Chemistry 3, 377-385.

Douglas, G., Palmer, M. and Caitcheon, G., 2003. The provenance of sediments in Moreton Bay, Australia: a synthesis of major, trace element and $\mathrm{Sr}-\mathrm{Nd}-\mathrm{Pb}$ isotopic geochemistry, modelling and landscape analysis. Hydrobiologia 494, 145-152.

Droppo, I., Nackaerts, K., Walling, D. and Williams, N., 2005. Can flocs and water stable soil aggregates be differentiated within fluvial systems? CATENA 60, 1-18.

Droppo, I., Walling, D. and Ongley, E., 1998. Suspended sediment structure: implications for sediment and contaminant transport modelling. In: W. Summer, E. Klaghofer and W. Zhang (Editors), Modelling Soil Erosion, Sediment Transport and Closely Related Hydrological Processes, IAHS Publication No. 249, IAHS Press, Wallingford, 437-444.

Dyer, F.J. and Olley, J.M., 1999. The effects of grain abrasion and disaggregation on ${ }^{137} \mathrm{Cs}$ concentrations in different size fractions of soils developed on three different rock types. CATENA 36, 143-151.

Ehrlich, R., Brown, P.J., Yarus, J.M. and Przygocki, R.S., 1980. The origin of shape frequency distributions and the relationship between size and shape. Journal of Sedimentary Research 50, 475-483. 
Evrard, O., Laceby, J.P., Huon, S., Lefèvre, I., Sengtaheuanghoung, O. and Ribolzi, O., 2016. Combining multiple fallout radionuclides $\left({ }^{137} \mathrm{Cs},{ }^{7} \mathrm{Be},{ }^{210} \mathrm{~Pb}_{\mathrm{xs}}\right)$ to investigate temporal sediment source dynamics in tropical, ephemeral riverine systems. Journal of Soils and Sediments 16, 1130-1144.

Evrard, O., Navratil, O., Ayrault, S., Ahmadi, M., Némery, J., Legout, C., Lefèvre, I., Poirel, A., Bonté, P. and Esteves, M., 2011. Combining suspended sediment monitoring and fingerprinting to determine the spatial origin of fine sediment in a mountainous river catchment. Earth Surface Processes and Landforms 36, 1072-1089.

Evrard, O., Némery, J., Gratiot, N., Duvert, C., Ayrault, S., Lefèvre, I., Poulenard, J., Prat, C., Bonté, P. and Esteves, M., 2010. Sediment dynamics during the rainy season in tropical highland catchments of central Mexico using fallout radionuclides. Geomorphology 124, 42-54.

Evrard, O., Poulenard, J., Nemery, J., Ayrault, S., Gratiot, N., Duvert, C., Prat, C., Lefèvre, I., Bonté, P. and Esteves, M., 2013. Tracing sediment sources in a tropical highland catchment of central Mexico by using conventional and alternative fingerprinting methods. Hydrological Processes 27, 911-922.

Fan, Q., Yamaguchi, N., Tanaka, M., Tsukada, H. and Takahashi, Y., 2014. Relationship between the adsorption species of cesium and radiocesium interception potential in soils and minerals: an EXAFS study. Journal of Environmental Radioactivity 138, 92-100.

Fontaine, T.A., Moore, T.D. and Burgoa, B., 2000. Distributions of contaminant concentration and particle size in fluvial sediment. Water Research 34, 3473-3477.

Foster, I.D.L., Lees, J.A., Owens, P.N. and Walling, D.E., 1998. Mineral magnetic characterization of sediment sources from an analysis of lake and floodplain sediments in the catchments of the Old Mill Reservoir and Slapton Ley, South Devon, UK. Earth Surface Processes and Landforms 23, 685703.

Foucher, A., Laceby, J.P., Salvador-Blanes, S., Evrard, O., Le Gall, M., Lefèvre, I., Cerdan, O., Rajkumar, V. and Desmet, M., 2015. Quantifying the dominant sources of sediment in a drained lowland agricultural catchment: The application of a thorium-based particle size correction in sediment fingerprinting. Geomorphology 250, 271-281.

Fox, J.F. and Papanicolaou, A.N., 2007. The use of carbon and nitrogen isotopes to study watershed erosion processes. Journal of the American Water Resources Association 43, 1047-1064.

Freebairn, D. and Wockner, G., 1986. A study of soil erosion on vertisols of the eastern Darling Downs, Queensland .II. The effect of soil, rainfall, and flow conditions on suspended sediment losses. Soil Research 24, 159-172.

Frings, R.M., 2008. Downstream fining in large sand-bed rivers. Earth-Science Reviews 87, 39-60.

Fry, B., 2006. Stable Isotope Ecology. Springer. New York., 308 pp.

Garzon-Garcia, A., Laceby, J.P., Olley, J.M. and Bunn, S.E., 2017. Differentiating the sources of fine sediment, organic matter and nitrogen in a subtropical Australian catchment. Science of The Total Environment 575, 1384-1394.

Gateuille, D., Evrard, O., Lefevre, I., Moreau-Guigon, E., Alliot, F., Chevreuil, M. and Mouchel, J.-M., 2014. Mass balance and decontamination times of Polycyclic Aromatic Hydrocarbons in rural nested catchments of an early industrialized region (Seine River basin, France). Science of The Total Environment 470, 608-617.

Gerlach, T., 1967. Hillslope troughs for measuring sediment movement. Revue de Geomorphologie Dynamique 17, 173.

Gibbs, M., 2008. Identifying source soils in contemporary estuarine sediments: A new compound-specific isotope method. Estuaries and Coasts 31, 344-359.

Gibbs, R.J., 1967. Amazon River: Environmental Factors That Control Its Dissolved and Suspended Load. Science 156, 1734-1737.

Gibbs, R.J., Matthews, M.D. and Link, D.A., 1971. The relationship between sphere size and settling velocity. Journal of Sedimentary Research 41, 7-18. 
Gingele, F. and De Deckker, P., 2004. Fingerprinting Australia's rivers with clay minerals and the application for the marine record of climate change. Australian Journal of Earth Sciences 51, 339-348.

Gourdin, E., Evrard, O., Huon, S., Reyss, J.-L., Ribolzi, O., Bariac, T., Sengtaheuanghoung, O., Ayrault, S. and A.L., C., 2014. Spatial and temporal variability of ${ }^{7} \mathrm{Be}$ and ${ }^{210} \mathrm{~Pb}$ wet deposition during four successive monsoon storms in a catchment of northern Laos. Journal of Environmental Radioactivity 136, 195-205.

Gregorich, E., Beare, M., McKim, U. and Skjemstad, J., 2006. Chemical and biological characteristics of physically uncomplexed organic matter. Soil Science Society of America Journal 70, 975-985.

Grosbois, C., Meybeck, M., Lestel, L., Lefèvre, I. and Moatar, F., 2012. Severe and contrasted polymetallic contamination patterns (1900-2009) in the Loire River sediments (France). Science of The Total Environment 435, 290-305.

Guzmán, G., Quinton, J., Nearing, M., Mabit, L. and Gómez, J., 2013. Sediment tracers in water erosion studies: current approaches and challenges. Journal of Soils and Sediments 13, 816-833.

Haddadchi, A., Olley, J. and Laceby, J.P., 2014. Accuracy of mixing models in predicting sediment source contributions. Science of The Total Environment 497-498, 139-152.

Haddadchi, A., Olley, J. and Pietsch, T., 2015. Quantifying sources of suspended sediment in three size fractions. Journal of Soils and Sediments 15, 2086-2100.

Haddadchi, A., Ryder, D.S., Evrard, O. and Olley, J., 2013. Sediment fingerprinting in fluvial systems: review of tracers, sediment sources and mixing models. International Journal of Sediment Research 28, 560-578.

Hancock, G.J. and Revill, A.T., 2013. Erosion source discrimination in a rural Australian catchment using compound-specific isotope analysis (CSIA). Hydrological Processes 27, 923-932.

Hardy, F., Bariteau, L., Lorrain, S., Theriault, I., Gagnon, G., Messier, D. and Rougerie, J.F., 2010. Geochemical tracing and spatial evolution of the sediment bed load of the Romaine River, Quebec, Canada. CATENA 81, 66-76.

Hatfield, R.G., 2014. Particle size-specific magnetic measurements as a tool for enhancing our understanding of the bulk magnetic properties of sediments. Minerals 4, 758-787.

Hatfield, R.G. and Maher, B.A., 2008. Suspended sediment characterization and tracing using a magnetic fingerprinting technique: Bassenthwaite Lake, Cumbria, UK. The Holocene 18, 105-115.

Hatfield, R.G. and Maher, B.A., 2009. Fingerprinting upland sediment sources: particle size-specific magnetic linkages between soils, lake sediments and suspended sediments. Earth Surface Processes and Landforms 34, 1359-1373.

He, Q. and Owens, P.N., 1995. Determination of suspended sediment provenance using caesium-137, unsupported lead-210 and radium-226: a numerical mixing model approach. In: I. Foster, A. Gurnell and B. Webb (Editors), Sediment and Water Quality in River Catchments, Wiley, Chichester, 207-227.

$\mathrm{He}, \mathrm{Q}$. and Walling, D.E., 1996. Interpreting particle size effects in the adsorption of ${ }^{137} \mathrm{Cs}$ and unsupported ${ }^{210} \mathrm{~Pb}$ by mineral soils and sediments. Journal of Environmental Radioactivity 30, 117-137.

Horowitz, A.J., 1991. A primer on sediment-trace element chemistry, 2nd edition. Open-File Report 91-76, United States Geological Survey; Books and Open-File Reports Section, Denver, Colorado, 136 pp.

Horowitz, A.J. and Elrick, K.A., 1987. The relation of stream sediment surface area, grain size and composition to trace element chemistry. Applied Geochemistry 2, 437-451.

Hughes, A.O., Olley, J.M., Croke, J.C. and McKergow, L.A., 2009. Sediment source changes over the last 250 years in a dry-tropical catchment, central Queensland, Australia. Geomorphology 104, 262-275.

IAEA, 2014. Guidelines for Using Fallout Radionuclides to Assess Erosion and Effectiveness of Soil Conservation Strategies, IAEA (International Atomic Energy Agency) publication, IAEA-TECDOC1741. Vienna, Austria, 213 pp. 
934

935

936

937

938

939

940

941

942

943

944

945

946

947

948

949

950

951

952

953

954

955

956

957

958

959

960

961

962

963

964

965

966

967

968

969

970

971

972

973

974

975

976

977

978

979

980

981

Jagercikova, M., Cornu, S., Le Bas, C. and Evrard, O., 2015. Vertical distributions of ${ }^{137}$ Cs in soils: a metaanalysis. Journal of Soils and Sediments 15, 81-95.

Keil, R.G. and Mayer, L.M., 2014. 12.12 - Mineral Matrices and Organic Matter A2 - Holland, Heinrich D. In: K.K. Turekian (Editor), Treatise on Geochemistry (Second Edition). Elsevier, Oxford, 337-359.

Kersten, M. and Smedes, F., 2002. Normalization procedures for sediment contaminants in spatial and temporal trend monitoring. Journal of Environmental Monitoring 4, 109-115.

Klages, M.G. and Hsieh, Y.P., 1975. Suspended solids carried by the Gallatin River of southwestern Montana: Il. Using minerology for inferring sources. Journal of Environmental Quality 4, 68-73.

Koiter, A., Lobb, D., Owens, P., Petticrew, E., Tiessen, K.D. and Li, S., 2013a. Investigating the role of connectivity and scale in assessing the sources of sediment in an agricultural watershed in the Canadian prairies using sediment source fingerprinting. Journal of Soils and Sediments 13, 16761691.

Koiter, A.J., Owens, P.N., Petticrew, E.L. and Lobb, D.A., 2013b. The behavioural characteristics of sediment properties and their implications for sediment fingerprinting as an approach for identifying sediment sources in river basins. Earth-Science Reviews 125, 24-42.

Koiter, A.J., Owens, P.N., Petticrew, E.L. and Lobb, D.A., 2015. The role of gravel channel beds on the particle size and organic matter selectivity of transported fine-grained sediment: implications for sediment fingerprinting and biogeochemical flux research. Journal of Soils and Sediments 15, 2174-2188.

Koiter, A.J., Owens, P.N., Petticrew, E.L. and Lobb, D.A., 2017. The role of soil surface properties on the particle size and carbon selectivity of interrill erosion in agricultural landscapes. CATENA 153, 194206.

Kraushaar, S., Schumann, T., Ollesch, G., Schubert, M., Vogel, H.-J. and Siebert, C., 2015. Sediment fingerprinting in northern Jordan: element-specific correction factors in a carbonatic setting. Journal of Soils and Sediments 15, 2155-2173.

Krumbein, W.C. and Sloss, L.L., 1951. Stratigraphy and sedimentation. Soil Science 71, 401.

Laceby, J.P., Huon, S., Onda, Y. and Evrard, O., 2016. Do forests represent a long-term source of contaminated particulate matter in the Fukushima Prefecture? Journal of Environmental Management 183, 742-753.

Laceby, J.P., McMahon, J., Evrard, O. and Olley, J., 2015a. A comparison of geological and statistical approaches to element selection for sediment fingerprinting. Journal of Soils and Sediments 15, 2117-2131.

Laceby, J.P. and Olley, J., 2015. An examination of geochemical modelling approaches to tracing sediment sources incorporating distribution mixing and elemental correlations. Hydrological Processes 29, 1669-1685

Laceby, J.P., Olley, J., Pietsch, T.J., Sheldon, F. and Bunn, S.E., 2015b. Identifying subsoil sediment sources with carbon and nitrogen stable isotope ratios. Hydrological Processes 29, 1956-1971.

Le Cloarec, M.F., Bonte, P.H., Lestel, L., Lefèvre, I. and Ayrault, S., 2011. Sedimentary record of metal contamination in the Seine River during the last century. Physics and Chemistry of the Earth, Parts A/B/C 36, 515-529.

Le Gall, M., Evrard, O., Foucher, A., Laceby, J.P., Salvador-Blanes, S., Thil, F., Dapoigny, A., Lefèvre, I., Cerdan, O. and Ayrault, S., 2016. Quantifying sediment sources in a lowland agricultural catchment pond using ${ }^{137} \mathrm{Cs}$ activities and radiogenic ${ }^{87} \mathrm{Sr} /{ }^{86} \mathrm{Sr}$ ratios. Science of The Total Environment 566567, 968-980.

Le, M.H., Cordier, S., Lucas, C. and Cerdan, O., 2015. A faster numerical scheme for a coupled system modeling soil erosion and sediment transport. Water Resources Research 51, 987-1005.

Lewis, J., 1996. Turbidity-controlled suspended sediment sampling for runoff-event load estimation. Water Resources Research 32, 2299-2310. 
982

983

984

985

986

987

988

989

990

991

992

993

994

995

996

997

998

999

1000

1001

1002

1003

1004

1005

1006

1007

1008

1009

1010

1011

1012

1013

1014

1015

1016

1017

1018

1019

1020

1021

1022

1023

1024

1025

1026

1027

1028

Lomenick, T.F. and Tamura, T., 1965. Naturally Occurring Fixation of Cesium-137 on Sediments of Lacustrine Origin. Soil Science Society of America Journal 29, 383-387.

Mabit, L., Benmansour, M., Abril, J.M., Walling, D.E., Meusburger, K., lurian, A.R., Bernard, C., Tarján, S., Owens, P.N. and Blake, W.H., 2014. Fallout ${ }^{210} \mathrm{~Pb}$ as a soil and sediment tracer in catchment sediment budget investigations: a review. Earth-Science Reviews 138, 335-351.

Martinez-Carreras, N., Udelhoven, T., Krein, A., Gallart, F., Iffly, J.F., Ziebel, J., Hoffmann, L., Pfister, L. and Walling, D.E., 2010. The use of sediment colour measured by diffuse reflectance spectrometry to determine sediment sources: Application to the Attert River catchment (Luxembourg). Journal of Hydrology 382, p 49-63.

Matisoff, G., Bonniwell, E.C. and Whiting, P.J., 2002. Soil erosion and sediment sources in an Ohio watershed using Beryllium-7, Cesium-137, and Lead-210. Journal of Environmental Quality 31, 5461.

Matisoff, G., Wilson, C.G. and Whiting, P.J., 2005. The ${ }^{7} \mathrm{Be} /{ }^{210} \mathrm{~Pb}$ xs ratio as an indicator of suspended sediment age or fraction new sediment in suspension. Earth Surface Processes and Landforms 30, 1191-1201.

Mayer, L., 1999. Extent of coverage of mineral surfaces by organic matter in marine sediments. Geochimica et Cosmochimica Acta 63, 207-215.

McCulloch, M., Fallon, S., Wyndham, T., Hendy, E., Lough, J. and Barnes, D., 2003. Coral record of increased sediment flux to the inner Great Barrier Reef since European settlement. Nature 421, 727-730.

McLaren, P. and Bowles, D., 1985. The effects of sediment transport on grain-size distributions. Journal of Sedimentary Research 55, 457-470.

Merkus, H.G., 2009. Particle Size Measurements: Fundamentals, Practice, Quality, 17. Springer Science \& Business Media, $532 \mathrm{pp}$.

Morgan, R., 2005. Soil Erosion and Conservation, Third Edition. Blackwell Publishing, Oxford, 303 pp.

Morris, G.L. and Fan, J., 1998. Reservoir Sedimentation Handbook: Design and Management of Dams, Reservoirs, and Watersheds for Sustainable Use. McGraw Hill Professional, New York, 848 pp.

Moss, A. and Walker, P., 1978. Particle transport by continental water flows in relation to erosion, deposition, soils, and human activities. Sedimentary Geology 20, 81-139.

Motha, J.A., Wallbrink, P.J., Hairsine, P.B. and Grayson, R.B., 2002. Tracer properties of eroded sediment and source material. Hydrological Processes 16, 1983-2000.

Motha, J.A., Wallbrink, P.J., Hairsine, P.B. and Grayson, R.B., 2003. Determining the sources of suspended sediment in a forested catchment in southeastern Australia. Water Resources Research 39, 1056.

Mukundan, R., Radcliffe, D.E., Ritchie, J.C., Risse, L.M. and Mckinley, R.A., 2010. Sediment fingerprinting to determine the source of suspended sediment in a southern piedmont stream. Journal of Environmental Quality 39, 1328-1337.

Mukundan, R., Walling, D.E., Gellis, A.C., Slattery, M.C. and Radcliffe, D.E., 2012. Sediment Source Fingerprinting: Transforming From a Research Tool to a Management Tool. Journal of the American Water Resources Association 48, 1241-1257.

Murray, A., Stanton, R., Olley, J. and Morton, R., 1993a. Determining the origins and history of sedimentation in an underground river system using natural and fallout radionuclides. Journal of Hydrology 146, 341-359.

Murray, A.S., Olive, L.J., Olley, J.M., Caitcheon, G.G., Wasson, R.J. and Wallbrink, P.J., 1993b. Tracing the Source of Suspended Sediment in the Murrumbidgee River, Australia. In: N.E. Peters, E. Hoehn, C. Leibundgut, N. Tase and D.E. Walling (Editors), Tracers in Hydrology, IAHS Publication No. 215, IAHS Press, Wallingford, 293-302.

Natelhoffer, K.J. and Fry, B., 1988. Controls on natural nitrogen-15 and carbon-13 abundances in forest soil organic matter. Soil Science Society of America Journal 52, 1633-1640. 
1029

1030

1031

1032

1033

1034

1035

1036

1037

1038

1039

1040

1041

1042

1043

1044

1045

1046

1047

1048

1049

1050

1051

1052

1053

1054

1055

1056

1057

1058

1059

1060

1061

1062

1063

1064

1065

1066

1067

1068

1069

1070

1071

1072

1073

1074

1075

1076

Navratil, O., Evrard, O., Esteves, M., Legout, C., Ayrault, S., Némery, J., Mate-Marin, A., Ahmadi, M., Lefèvre, I. and Poirel, A., 2012. Temporal variability of suspended sediment sources in an alpine catchment combining river/rainfall monitoring and sediment fingerprinting. Earth Surface Processes and Landforms 37, 828-846.

Oldfield, F., 1991. Environmental magnetism - A personal perspective. Quaternary Science Reviews 10, 73-85.

Oldfield, F., Maher, B., Donoghue, J. and Pierce, J., 1985. Particle-size related, mineral magnetic source sediment linkages in the Rhode River catchment, Maryland, USA. Journal of the Geological Society $142,1035-1046$.

Olley, J., Burton, J., Smolders, K., Pantus, F. and Pietsch, T., 2013. The application of fallout radionuclides to determine the dominant erosion process in water supply catchments of subtropical South-east Queensland, Australia. Hydrological Processes 27, 885-895.

Olley, J. and Caitcheon, G., 2000. Major element chemistry of sediments from the Darling-Barwon river and its tributaries: implications for sediment and phosphorus sources. Hydrological Processes 14, 1159-1175.

Olley, J.M., 2002. Organic carbon supply to a large lowland river and implications for aquatic ecosystems. In: F.J. Dyer, M.C. Thoms and J.M. Olley (Editors), The Structure Function and Management Implications of Fluvial Sedimentary Systems, IAHS Publication No. 276, IAHS Press, Wallingford, 27-33.

Olley, J.M., Caitcheon, G.G., Hancock, G. and Wallbrink, P.J., 2001. Tracing and Dating Techniques for Sediment and Associated Substances. CSIRO Land and Water, Canberra.

Olley, J.M. and Murray, A.S., 1994. Origins of variability in the ${ }^{230} \mathrm{Th} /{ }^{232} \mathrm{Th}$ ratio in sediments. In: D.E. Walling and Q. He (Editors), Variability in Stream Erosion and Sediment Transport, IAHS Publication No. 224, IAHS Press, Wallingford, 65-70.

Ortiz, J.D., Polyak, L., Grebmeier, J.M., Darby, D., Eberl, D.D., Naidu, S. and Nof, D., 2009. Provenance of Holocene sediment on the Chukchi-Alaskan margin based on combined diffuse spectral reflectance and quantitative X-Ray Diffraction analysis. Global and Planetary Change 68, 73-84.

Owens, P.N., Batalla, R.J., Collins, A.J., Gomez, B., Hicks, D.M., Horowitz, A.J., Kondolf, G.M., Marden, M., Page, M.J., Peacock, D.H., Petticrew, E.L., Salomons, W. and Trustrum, N.A., 2005. Fine-grained sediment in river systems: environmental significance and management issues. River Research and Applications 21, 693-717.

Owens, P.N., Blake, W.H., Gaspar, L., Gateuille, D., Koiter, A.J., Lobb, D.A., Petticrew, E.L., Raiffarth, D., Smith, H.G. and Woodward, J.C., 2016. Fingerprinting and tracing the sources of soils and sediments: earth and ocean science, geoarchaeological, forensic, and human health applications. Earth-Science Reviews 162, 1-23.

Owens, P.N., Blake, W.H., Giles, T.R. and Williams, N.D., 2012. Determining the effects of wildfire on sediment sources using ${ }^{137} \mathrm{Cs}$ and unsupported ${ }^{210} \mathrm{~Pb}$ : the role of landscape disturbances and driving forces. Journal of Soils and Sediments 12, 982-994.

Owens, P.N., Blake, W.H. and Petticrew, E.L., 2006. Changes in sediment sources following wildfire in mountainous terrain: A paired-catchment approach, British Columbia, Canada. In: B. Kronvang, J. Faganeli and N. Ogrinc (Editors), The Interactions Between Sediments and Water. Springer Netherlands, 273-281.

Owens, P.N., Walling, D.E. and Leeks, G.J.L., 2000. Tracing fluvial suspended sediment sources in the catchment of the River Tweed, Scotland, using composite fingerprints and a numerical mixing model. In: I. Foster (Editor), Tracers in Geomorphology. Wiley, Chichester, 291-308.

Palazón, L., Gaspar, L., Latorre, B., Blake, W. and Navas, A., 2015a. Identifying sediment sources by applying a fingerprinting mixing model in a Pyrenean drainage catchment. Journal of Soils and Sediments 15, 2067-2085. 
1077

1078

1079

1080

1081

1082

1083

1084

1085

1086

1087

1088

1089

1090

1091

1092

1093

1094

1095

1096

1097

1098

1099

1100

1101

1102

1103

1104

1105

1106

1107

1108

1109

1110

1111

1112

1113

1114

1115

1116

1117

1118

1119

1120

1121

1122

1123

1124

Palazón, L., Latorre, B., Gaspar, L., Blake, W.H., Smith, H.G. and Navas, A., 2015b. Comparing catchment sediment fingerprinting procedures using an auto-evaluation approach with virtual sample mixtures. Science of The Total Environment 532, 456-466.

Panuska, J.C., Karthikeyan, K.G. and Miller, P.S., 2008. Impact of surface roughness and crusting on particle size distribution of edge-of-field sediments. Geoderma 145, 315-324.

Papanicolaou, A.N., Fox, J.F. and Marshall, J., 2003. Soil fingerprinting in the Palouse Basin, USA using stable carbon and nitrogen isotopes. International Journal of Sediment Research 18, 278-284.

Peart, M.R. and Walling, D.E. (Editors), 1986. Fingerprinting sediment source: The example of a drainage basin in Devon, UK. Drainage Basin Sediment Delivery, IAHS Publication No. 159, IAHS PresS, Wallingford, 41-55 pp.

Phillips, J. and Walling, D., 1995. An assessment of the effects of sample collection, storage and resuspension on the representativeness of measurements of the effective particle size distribution of fluvial suspended sediment. Water Research 29, 2498-2508.

Poesen, J., 1992. Mechanisms of overland-flow generation and sediment production on loamy and sandy soils with and without rock fragments. In: A.J. Parsons and A.D. Abrahams (Editors), Overland Flow Hydraulics and Erosion Mechanics. Routledge, London, 275-305.

Poleto, C., Merten, G.H. and Minella, J.P., 2009. The identification of sediment sources in a small urban watershed in southern Brazil: An application of sediment fingerprinting. Environmental Technology 30, 1145-1153.

Poulenard, J., Legout, C., Némery, J., Bramorski, J., Navratil, O., Douchin, A., Fanget, B., Perrette, Y., Evrard, O. and Esteves, M., 2012. Tracing sediment sources during floods using Diffuse Reflectance Infrared Fourier Transform Spectrometry (DRIFTS): A case study in a highly erosive mountainous catchment (Southern French Alps). Journal of Hydrology 414-415, 452-462.

Poulenard, J., Perrette, Y., Fanget, B., Quetin, P., Trevisan, D. and Dorioz, J.M., 2009. Infrared spectroscopy tracing of sediment sources in a small rural watershed (French Alps). Science of The Total Environment 407, 2808-2819.

Pulley, S., Foster, I. and Antunes, P., 2015a. The application of sediment fingerprinting to floodplain and lake sediment cores: assumptions and uncertainties evaluated through case studies in the Nene Basin, UK. Journal of Soils and Sediments, 1-23.

Pulley, S., Rowntree, K. and Foster, I., 2015b. Conservatism of mineral magnetic signatures in farm dam sediments in the South African Karoo: the potential effects of particle size and post-depositional diagenesis. Journal of Soils and Sediments 15, 2387-2397.

Rawlins, B.G., Turner, G., Mounteney, I. and Wildman, G., 2010. Estimating specific surface area of fine stream bed sediments from geochemistry. Applied Geochemistry 25, 1291-1300.

Reiffarth, D.G., Petticrew, E.L., Owens, P.N. and Lobb, D.A., 2016. Sources of variability in fatty acid (FA) biomarkers in the application of compound-specific stable isotopes (CSSIs) to soil and sediment fingerprinting and tracing: A review. Science of The Total Environment 565, 8-27.

Russell, M.A., Walling, D.E. and Hodgkinson, R.A., 2001. Suspended sediment sources in two small lowland agricultural catchments in the UK. Journal of Hydrology 252, 1-24.

Schimel, D.S., 1993. Theory and Application of Tracers. Isotopic Techniques in Plant, Soil and Aquatic Biology. Academic Press, Inc., San Diego., 119 pp.

Sherriff, S.C., Franks, S.W., Rowan, J.S., Fenton, O. and Ó’hUallacháin, D., 2015. Uncertainty-based assessment of tracer selection, tracer non-conservativeness and multiple solutions in sediment fingerprinting using synthetic and field data. Journal of Soils and Sediments 10, 2101-2116.

Singh, M., Sharma, M. and Tobschall, H.J., 2005. Weathering of the Ganga alluvial plain, northern India: implications from fluvial geochemistry of the Gomati River. Applied Geochemistry 20, 1-21.

Singleton, A.A., Schmidt, A.H., Bierman, P.R., Rood, D.H., Neilson, T.B., Greene, E.S., Bower, J.A. and Perdrial, N., 2017. Effects of grain size, mineralogy, and acid-extractable grain coatings on the 
distribution of the fallout radionuclides $7 \mathrm{Be}, 10 \mathrm{Be}, 137 \mathrm{Cs}$, and $210 \mathrm{~Pb}$ in river sediment. Geochimica et Cosmochimica Acta 197, 71-86.

Slattery, M.C., Burt, T.P. and Walden, J., 1995. The application of mineral magnetic measurements to quantify within-storm variations in suspended sediment sources. In: C. Leibundgut (Editor), Tracer Technologies for Hydrological Systems, IAHS Publication No. 229, IAHS Press, Wallingford, 143152.

Smith, H.G. and Blake, W.H., 2014. Sediment fingerprinting in agricultural catchments: A critical reexamination of source discrimination and data corrections. Geomorphology 204, 177-191.

Smith, H.G., Blake, W.H. and Owens, P.N., 2013. Discriminating fine sediment sources and the application of sediment tracers in burned catchments: a review. Hydrological Processes 27, 943-958.

Smith, H.G., Blake, W.H. and Taylor, A., 2014. Modelling particle residence times in agricultural river basins using a sediment budget model and fallout radionuclide tracers. Earth Surface Processes and Landforms 39, 1944-1959.

Smith, H.G., Sheridan, G.J., Lane, P.N., Noske, P.J. and Heijnis, H., 2011. Changes to sediment sources following wildfire in a forested upland catchment, southeastern Australia. Hydrological Processes 25, 2878-2889.

Smith, J., 1999. An introduction to the magnetic properties of natural materials. Environmental Magnetism: A Practical Guide. Technical Guide 6, 5-34.

Stone, M., Collins, A., Silins, U., Emelko, M. and Zhang, Y., 2014. The use of composite fingerprints to quantify sediment sources in a wildfire impacted landscape, Alberta, Canada. Science of The Total Environment 473, 642-650.

Stone, P. and Walling, D., 1997. Particle size selectivity considerations in suspended sediment budget investigations. In: R.D. Evans, J. Wisniewski and J.R. Wisniewski (Editors), The Interactions Between Sediments and Water, Springer, Netherlands, 63-70.

Stout, J.C., Belmont, P., Schottler, S.P. and Willenbring, J.K., 2014. Identifying sediment sources and sinks in the Root River, Southeastern Minnesota. Annals of the Association of American Geographers 104, 20-39.

Stumm, W. and Morgan, J.J., 2012. Aquatic Chemistry: Chemical Equilibria and rates in Natural Waters. John Wiley \& Sons, Chichester, 1040 pp.

Szava-Kovats, R.C., 2008. Grain-size normalization as a tool to assess contamination in marine sediments: Is the $<63 \mu \mathrm{m}$ fraction fine enough? Marine Pollution Bulletin 56, 629-632.

Tamura, T., 1964. Consequences of activity release: selective sorption reactions of cesium with soil minerals. Nuclear Safety 5, 262-268.

Taylor, A., Blake, W.H. and Keith-Roach, M.J., 2014. Estimating Be-7 association with soil particle size fractions for erosion and deposition modelling. Journal of Soils and Sediments 14, 1886-1893.

Taylor, A., Blake, W.H., Smith, H.G., Mabit, L. and Keith-Roach, M.J., 2013. Assumptions and challenges in the use of fallout beryllium-7 as a soil and sediment tracer in river basins. Earth-Science Reviews 126, 85-95.

Tiecher, T., Caner, L., Minella, J.P.G., Bender, M.A. and dos Santos, D.R., 2016. Tracing sediment sources in a subtropical rural catchment of southern Brazil by using geochemical tracers and near-infrared spectroscopy. Soil and Tillage Research 155, 478-491.

Vale, S.S., Fuller, I.C., Procter, J.N., Basher, L.R. and Smith, I.E., 2016. Characterization and quantification of suspended sediment sources to the Manawatu River, New Zealand. Science of The Total Environment 543, 171-186.

Vercruysse, K., Grabowski, R.C. and Rickson, R.J., 2017. Suspended sediment transport dynamics in rivers: Multi-scale drivers of temporal variation. Earth-Science Reviews 166, 38-52.

Viparelli, E., Wesley Lauer, J., Belmont, P. and Parker, G., 2013. A numerical model to develop long-term sediment budgets using isotopic sediment fingerprints. Computers \& Geosciences 53, 114-122. 
1173

1174

1175

1176

1177

1178

1179

1180

1181

1182

1183

1184

1185

1186

1187

1188

1189

1190

1191

1192

1193

1194

1195

1196

1197

1198

1199

1200

1201

1202

1203

1204

1205

1206

1207

1208

1209

1210

1211

1212

1213

1214

1215

1216

1217

1218

1219

1220
Walden, J. and Slattery, M.C., 1993. Verification of a simple gravity technique for separation of particle size fractions suitable for mineral magnetic analysis. Earth Surface Processes and Landforms 18, 829-833.

Wall, G.J. and Wilding, L.P., 1975. Minerology and Related Parameters of Fluvial Suspended Sediments in Norwesthern Ohio. Journal of Environmental Quality 5, 168-173.

Wallbrink, P. and Murray, A., 1996a. Distribution and variability of 7Be in soils under different surface cover conditions and its potential for describing soil redistribution processes. Water Resources Research 32, 467-476.

Wallbrink, P.J. and Murray, A.S., 1993. Use of fallout radionuclides as indicators of erosion processes. Hydrological Processes 7, 297-304.

Wallbrink, P.J. and Murray, A.S., 1996b. Determining Soil Loss Using The Inventory Ratio Of Excess-Lead 210 To Cesium-137. Soil Science Society of America Journal 60, 1201-1208.

Wallbrink, P.J., Murray, A.S., Olley, J.M. and Olive, L.J., 1998. Determining sources and transit times of suspended sediment in the Murrumbidgee River, New South Wales, Australia, using fallout ${ }^{137} \mathrm{Cs}$ and ${ }^{210} \mathrm{~Pb}$. Water Resources Research 34, 879-887.

Wallbrink, P.J., Olley, J.M. and Murray, A.S., 1999. Relating suspended sediment to its original soil depth using fallout radionuclides. Soil Science Society of America Journal 63, 369-378.

Walling, D. and Moorehead, P., 1989. The particle size characteristics of fluvial suspended sediment: an overview. Hydrobiologia 176, 125-149.

Walling, D., Peart, M., Oldfield, F. and Thompson, R., 1979. Suspended sediment sources identified by magnetic measurements. Nature 281, 110-113.

Walling, D.E., 2003. Using environmental radionuclides as tracers in sediment budget investigations. In: D.E. Walling and T. Fergus (Editors), Erosion and Sediment Transport Measurement in Rivers: Technological and Methodological Advances, IAHS Publication No. 283, IAHS Press, Wallingford, 57-78.

Walling, D.E., 2005. Tracing suspended sediment sources in catchments and river systems. Science of The Total Environment 344, 159-184.

Walling, D.E. and Collins, A.L., 2016. Fine sediment transport and management. In: D.J. Gilvear, M.T. Greenwood, M.C. Thoms and P.J. Wood (Editors), River Science: Research and Management for the 21st Century, John Wiley \& Sons, Chichester, 37-60.

Walling, D.E. and Kane, P., 1984. Suspended sediment properties and their geomorphological significance. In: T.P. Burt and D.E. Walling (Editors), Catchment Experiments in Fluvial Geomorphology, Geo Books, Norwich, 311-334.

Walling, D.E., Owens, P.N. and Leeks, G.J.L., 1999. Fingerprinting suspended sediment sources in the catchment of the River Ouse, Yorkshire, UK. Hydrological Processes 13, 955-975.

Walling, D.E., Owens, P.N., Waterfall, B.D., Leeks, G.J. and Wass, P.D., 2000. The particle size characteristics of fluvial suspended sediment in the Humber and Tweed catchments, UK. Science of The Total Environment 251, 205-222.

Walling, D.E. and Woodward, J.C., 1992. Use of radiometric fingerprints to derive information on suspended sediment sources In: J. Bogen, D.E. Walling and T. Day (Editors), Erosion and Sediment Transport Monitoring Programmes in River Basins, IAHS Publication No. 210, IAHS Press, Wallingford, 153-164.

Walling, D.E., Woodward, J.C. and Nicholas, A.P., 1993. A multi-parameter approach to fingerprinting suspended-sediment sources. In: N.E. Peters, E. Hoehn, C. Leibundgut, N. Tase and D.E. Walling (Editors), Tracers in Hydrology, IAHS Publication No. 215, IAHS Press, Wallingford, 329-338.

Wischmeier, W.H. and Smith, D.D., 1978. Predicting Rainfall Erosion Losses-A guide to Conservation Planning. Agricultural Handbook Number 537, United States Department of Agriculture, Science and Education Administration, Hyattsville, Maryland, 58 pp. 
1221

1222

1223

1224

1225

1226

1227

1228

1229

1230

1231

1232
Wohl, E., Bledsoe, B.P., Jacobson, R.B., Poff, N.L., Rathburn, S.L., Walters, D.M. and Wilcox, A.C., 2015. The Natural Sediment Regime in Rivers: Broadening the Foundation for Ecosystem Management. BioScience 65, 358-371.

Wynn, J.G., Bird, M.I. and Wong, V.N.L., 2005. Rayleigh distillation and the depth profile of ${ }^{13} \mathrm{C} /{ }^{12} \mathrm{C}$ ratios of soil organic carbon from soils of disparate texture in Iron Range National Park, Far North Queensland, Australia. Geochimica et Cosmochimica Acta 69, 1961-1973.

Yamashiki, Y., Onda, Y., Smith, H.G., Blake, W.H., Wakahara, T., Igarashi, Y., Matsuura, Y. and Yoshimura, K., 2014. Initial flux of sediment-associated radiocesium to the ocean from the largest river impacted by Fukushima Daiichi Nuclear Power Plant. Scientific Reports 4.

Zhang, X.J. and Liu, B., 2016. Using multiple composite fingerprints to quantify fine sediment source contributions: A new direction. Geoderma 268, 108-118. 